\title{
Heat budget of the surface mixed layer south of Africa
}

\author{
Vincent Faure ${ }^{1, a,{ }^{*},}$ Michel Arhan $^{1}$, Sabrina Speich ${ }^{2}$, Sergey Gladyshev ${ }^{3}$
}

\footnotetext{
${ }^{1}$ Laboratoire de Physique des Océans - UMR6523, CNRS/IFREMER/IRD/UBO, IFREMER/Centre de Brest, B.P. 70, 29280 Plouzané, France

2 Laboratoire de Physique des Océans - UMR6523, CNRS/IFREMER/IRD/UBO, UBO - UFR Sciences et Techniques, 6, Avenue Le Gorgeu, CS 93837, 29238 Brest Cedex 3, France

${ }^{3}$ Shirshov Institute of Oceanology Department of Marine Operations, 36 Nakhimovskii prospect, Moscow 117997, Russia,

a Present address : Research Institute for Global Change, Japan Agency for Marine-Earth Science and Technology (JAMSTEC), 2-15 Natsushima-cho, Yokosuka 237-0061 Japan
}

*: Corresponding author : Vincent Faure, Tel.: +81-46-867-9473 ; Fax: +81-46-867-9835 ;

email address : vfaure@jamstec.go.jp

\begin{abstract}
:
ARGO hydrographic profiles, two hydrographic transects, and satellite measurements of air-sea exchange parameters are used to characterize the properties and seasonal heat budget variations of the Surface Mixed Layer (SML) south of Africa. The analysis distinguishes the Subtropical domain (STZ), and the Subantarctic Zone (SAZ), Polar Frontal Zone (PFZ) and Antarctic Zone (AZ) of the Antarctic Circumpolar Current. While no Subantarctic Mode Water forms in that region, occurrences of deep SML (up to $\sim 450 \mathrm{~m}$ ) are observed in the SAZ in anticyclones detached from the Agulhas Current retroflection or Agulhas Return Current. These are present latitudinally throughout the SAZ, but preferentially at longitudes $10^{\circ} \mathrm{E}-20^{\circ} \mathrm{E}$ where, according to previous results, the Subtropical Front is interrupted. Likely owing to this exchange window and to transfers at the Subantarctic Front also enhanced by the anticyclones, the SAZ shows a wide range of properties largely encroaching upon those of the neighbouring domains. Heat budget computations in each zone reveal significant meridional changes of regime. While air-sea heat fluxes dictate the heat budget seasonal variability everywhere, heat is mostly brought through lateral geostrophic advection by the Agulhas Current in the STZ, through lateral diffusion in the SAZ, and through air-sea fluxes in the PFZ and AZ. The cooling contributions are by Ekman advection everywhere, lateral diffusion in the STZ (also favoured by the $\sim 10$-degree breach in the Subtropical Front), and by geostrophic advection in the SAZ. The latter likely reflects eastward draining of water warmed through mixing of the subtropical eddies.
\end{abstract}

Keywords: Ocean surface mixed layer ; Heat budget ; Southern Ocean ; Agulhas Current retroflection 


\section{1) Introduction}

While the oceanic region located south of South Africa has been studied extensively for its dynamical processes contributing to the transfer of Indian Ocean Central Water to the South Atlantic, other issues related to air-sea fluxes and water mass conversion, though also influencing inter-oceanic exchanges, have been comparatively less examined in this area than at other longitudes of the Southern Ocean. A reason for this certainly resides in the fact that no Subantarctic Mode Water (SAMW) is formed in the Subantarctic Zone south of Africa, unlike in the Indian Ocean and Pacific Ocean (McCartney, 1977; Sallée et al., 2008).

The northern part of this region, however, has particularities which would probably justify more research on issues related to air-sea exchanges. There, warm surface waters conveyed southward by the Agulhas Current find themselves overlaid by cold air a good fraction of the year. This, combined to persistent westerly and southwesterly winds, results in significant heat losses to the atmosphere (Walker and Mey, 1988), and generates Subtropical Mode waters with temperatures ranging between $\sim 14^{\circ} \mathrm{C}$ and $\sim 18^{\circ} \mathrm{C}$, which are found in the South Atlantic (Gordon et al., 1987; Olson et al., 1992). The heat losses to the atmosphere themselves cause a destabilisation of the marine atmospheric boundary layer (Lee-Thorp et al., 1998; Lutjeharms and Rouault, 2000), which results in a wind speed increase and strong ocean atmosphere coupling (Mey et al., 1990; O’Neill et al., 2005). South of the Subtropical Front (which marks the southern limit of Central Waters), the intense mesoscale activity of the region results in a southward diffusion of subtropical water properties into the Subantarctic Zone of the Antarctic Circumpolar Current (ACC). Sallée et al. $(2006,2008)$ showed that the ensuing warming of this zone is a factor preventing the formation of deep oceanic surface mixed layers (SML) north of the Subantarctic Front in the western Indian sector. Proceeding southward into the Polar Frontal Zone and Antarctic Zone, the near surface 
layer of the ACC south of Africa shows no obvious distinguishing feature, except that this region is near the longitude $\left(\sim 0^{\circ} \mathrm{E}\right)$ of northernmost extent of winter sea ice. Like at other longitudes, cold and fresh Antarctic Surface Water is conveyed in the Ekman layer equatorward across the fronts to the Subantarctic Zone. A difference perhaps again lies at the northern limit of this zone where, owing to intense mesoscale turbulence, the Subtropical Front may be regarded as porous (Dencausse et al., 2011), and the cold and fresh surface water proceeds northward across it more easily than at other longitudes.

As a first step toward more dedicated studies on the above issues, that will undoubtedly require working at the mesoscale, we here present an analysis of the seasonal heat budget of the SML in the region south of Africa, from $30^{\circ} \mathrm{S}$ to the southern boundary of the $\mathrm{ACC}$ at about $55^{\circ} \mathrm{S}$, and from $0^{\circ} \mathrm{E}$ to $40^{\circ} \mathrm{E}$. Studies on the heat balance of the upper ocean have been subject to strong interest renewal since the recent advent of autonomous ARGO profilers seeded in the whole ocean. Data from these floats, made available by the international ARGO project, are particularly precious in the Southern Ocean which has been historically undersampled. Two recent studies using ARGO floats, though not focused on the region south of Africa, provide information on the SML heat balance in this sector of the Southern Ocean. Sallée et al. (2006), while studying the formation of SAMW in the southeastern Indian Ocean, found that, upstream (west) of this formation area, heating by eddy diffusion related to the nearby South Indian western boundary current system (the Agulhas Current and Agulhas Return Current) counterbalances cooling due to air-sea fluxes and Ekman transport. Dong et al. (2007), in a circumpolar study of the Southern Ocean SML heat budget, underlined the role of air-sea fluxes at the seasonal time scale, and the relative weakness of the geostrophic advection term, in contrast with western boundary current regions. 
As our study domain lies where a western boundary current protrudes southward into the Southern Ocean, meridional changes in the relative importance of the terms contributing to the SML heat balance should be expected from the above results. In order to examine such possible meridional evolutions, the annual cycle of the SML heat budget was assessed separately in the Subtropical domain and in the three ACC frontal zones (Subantarctic, Polar Frontal and Antarctic zones), also using ARGO floats.

After characterizing the above-mentioned frontal zones in Section 2, the SML south of Africa is described in Section 3 using quasi-meridional hydrographic transects, and its seasonal variations in each frontal zone are discussed using the ARGO data. In Section 4 we present the heat budget equation and the way its different terms were computed. The annual cycles of the SML heat budget and contributing terms are analyzed in section 5 , before a discussion of the results in Section 6.

\section{2) The area of study and the four frontal zones}

Figure 1 showing a schematics of the surface circulation in the area of study, exhibits the three local major oceanic domains, namely, the Subtropical domain north of the Subtropical front (STF), the ACC between the STF and the Southern Boundary Front (SBy; Orsi et al., 1995), and the eastern part of the cyclonic Weddell gyre farther south. In Figure 1 are also shown the other fronts (Subantarctic: SAF; Polar: PF; Southern ACC: SACCF) listed by Orsi et al. (1995) as defining the ACC and, in the Subtropical domain, the Northern Subtropical Front (Belkin and Gordon, 1996), and the frontal pattern associated with the Agulhas Current and Agulhas Return Current. Based on this structure, the SML description and heat budget computations in this study are presented below in the so-called Subtropical Zone (STZ) north of the STF (disregarding the above-mentioned sub-areas of this zone), and in the classical ACC Subantarctic Zone (SAZ), Polar Frontal Zone (PFZ) and Antarctic Zone (AZ), the latter extending meridionally from the PF to the SBy disregarding the SACCF. 
The ACC fronts are generally determined using hydrographic criteria which, though unambiguous when working on hydrographic transects across the current, may be less reliable when trying to locate a single ARGO profile relative to a concomitant nearby front. For this reason, we took benefit from the generally monotonous northward increase of dynamic heights across the ACC, and we characterized the fronts locally by using the dynamic height at the surface, relative to $1500 \mathrm{dbar}\left(\mathrm{DH}_{0 / 1500}\right)$, a parameter which can be computed from the generally $2000 \mathrm{~m}$ deep ARGO profiles. In order to ascribe a value of $\mathrm{DH}_{0 / 1500}$ to each ACC front, we first determined the fronts positions in 6 available CTD (Conductivity-TemperatureDepth) transects across the ACC in that area (Table 1) using the hydrographic criteria proposed by Orsi et al. (1995). Of these CTD lines, four sampled the western part of the study area (AJAX, A12, A21, ASV-19), and two were realized along $30^{\circ} \mathrm{E}$ in the eastern part (I6, I6s). Using CTD stations flanking the fronts in these transects, we determined six $\mathrm{DH}_{0 / 1500}$ intervals encompassing each front. The final $\mathrm{DH}_{0 / 1500}$ value associated with a front was chosen as the middle of the segment common to the 6 intervals around this front (first column of Table 2). That a unique value of $\mathrm{DH}_{0 / 1500}$ may characterize the STF in this area appears somewhat contradictory to Dencausse et al. (2011), who found that the sea surface height associated with this front decreases by about $-0.10 \mathrm{~m}$ from $0^{\circ} \mathrm{E}$ to $30^{\circ} \mathrm{E}$. While not central to the 1.46-to- 1.58 dyn $\mathrm{m}$ interval which characterized the STF at $30^{\circ} \mathrm{E}$ during cruise $\mathrm{I} 6$, the retained value of 1.55 dyn $\mathrm{m}$, however, lies well within this interval and was therefore used for the whole area. Frontal dynamic height values reported in Table 2 should be regarded as regional values, not necessarily valid at other longitudes. In column 2 of the same table are $\mathrm{DH}_{0 / 1500}$ values of corresponding fronts from the circumpolar study of Sokolov and Rintoul (2009), who distinguished several branches for each ACC front. Retaining their branches with $\mathrm{DH}_{0 / 1500}$ values closest to the regional values in the first column, the corresponding values agree within 0.06 dyn $\mathrm{m}$ in the ACC. We note, however, that our Southern Boundary 
corresponds to the southern branch of the SACCF in Sokolov and Rintoul (2009), a likely result of their use of slightly different reference hydrographic criteria. Our STF $\mathrm{DH}_{0 / 1500}$ value is closest to that of their SAF northern branch, yet with a difference of 0.11 dyn $\mathrm{m}$. This approximately matches the $\sim 0.10$ dyn m zonal evolution of the STF dynamic height label mentioned above, with the 1.55 dyn m value possibly more representative of the western half of the study domain, and a value $\sim 1.45$ dyn m more representative of the eastern half. Also working at circumpolar scale, Sallée et al. (2008a) chose PF and SAF values (0.95 dyn m and 1.20 dyn $\mathrm{m}$, respectively; third column of Table 2).

The correspondence between hydrographic and $\mathrm{DH}_{0 / 1500}$ criteria is illustrated in Figure 2, which displays the potential temperature and salinity distributions along two realizations of a transect (the GoodHope line) shown in Figure 1. While the ASV-19 sampling of this line (Fig. 2a) was used for the determination of the $\mathrm{DH}_{0 / 1500}$ frontal values of Table 2, the more recent Marion Dufresne 2008 sampling (Fig.2b) was not, yet exhibits the same good correspondence between hydrographic and $\mathrm{DH}_{0 / 1500}$ - inferred fronts.

Figure 3a, showing the locations of the ARGO profiles used in this study with a colour code related to the $\mathrm{DH}_{0 / 1500}$ values of each frontal zone visualizes the equatorward increase of $\mathrm{DH}_{0 / 1500}$ across the ACC. Since each ARGO profile may be allocated a frontal zone, successive profiles (10-day separated) ascribed to different zones indicate that the ARGO float crossed a front. All such profile pairs were listed, and instantaneous front locations were estimated at equidistance from the geographical positions of the two profiles in each pair. Averaging these individual front locations over two degrees longitudinal bins then provides the ARGO-inferred averaged frontal patterns displayed in Figure $3 \mathrm{~b}$ along with Orsi et al. (1995) climatological tracks. The $\sim 2$ degree difference in latitude between the SAF track of Orsi et al. (1995) and that inferred from ARGO corroborates previous results (e.g., Legeais et al., 2005) which also located the SAF north of the climatology front in this region. The other 
ARGO-inferred tracks more closely follow their climatology counterparts, yet with some local deviations. These are the likely consequences of few front crossings by profilers at places (along the PF and SBy), or of intermingling of zones characteristics (Fig.3a), particularly along the STF. The latter observation points to the great variability of the STF location south of Africa (Dencausse et al., 2011), where eddies from both sides of the front are shed on the other side. This explains that $\mathrm{DH}_{0 / 1500}$ values typical of one side of the front may be observed in eddies at distance from it, on the other side.

\section{3) The Surface Mixed Layer south of Africa. Its mesoscale and seasonal variations}

a) Spring and summer sampling of the SML along the GoodHope line

The two temperature and salinity distributions displayed in Figure 2 are from spring (Fig.2a; November 8-25, 2004) and summer (Fig.2b; February 13-March 16, 2008). Both were realized in the framework of the GoodHope project, the former from $\mathrm{R} / \mathrm{V}$ Akademik Vavilov of the Shirshov Institute of Oceanology (Gladyshev et al., 2008), and the latter from R/V Marion Dufresne (Branellec et al., 2010). Following de Boyer Montegut et al. (2004), the depth of the mixed layer was determined using a threshold density criterion of $\Delta \rho=0.03 \mathrm{~kg} \mathrm{~m}^{-}$ ${ }^{3}$, where $\Delta \rho$ is the density difference from the uppermost value. Sallée et al. (2006), who also used this value, found it to be the most appropriate to monthly averaged applications, such as seasonal variability studies.

The depth of the SML thus computed is superimposed on the temperature and salinity vertical distributions of Figure 2. The general patterns of SML thickness were comparable during the two cruises, with weak values around 20-30 m north of the SAF increasing southward to $120-150 \mathrm{~m}$ across the PFZ, and keeping about the latter values in the AZ. This similarity reflects the presence of an incipient seasonal thermocline over nearly all the ACC in November 2004 (Fig.2a). Indeed, the only exception to this seems to be the domain south of $53^{\circ} \mathrm{S}$ (i.e., south of the SACCF; Fig.2a), where the SML reaches to $\sim 160 \mathrm{~m}$ depth, being 
underlaid by sharp thermocline and halocline. Farther north in the AZ, the SML is $\sim 120 \mathrm{~m}$ deep and underlaid by the Winter Water temperature minimum which, though less pronounced than in February-March (Fig.2b), extends northward to the PF, and even farther in the form of a detached Winter Water parcel. The northward shoaling of the SML in the PFZ seems governed by both temperature and salinity at the two seasons, while temperature is dominant in setting the SML depth in the STZ. Temperature seems therefore influential everywhere in determining the depth of the SML in these spring and summer sections, even though associated with salinity at places.

Extending the examination of temperature and salinity distributions downward beyond the SML, differences are visible between the two sections north of the SAF, which relate to the mesoscale variability. Starting with the STZ, the vertical cross-section of Central Water (typically characterized by salinities in excess of 35.0), was by far larger in November 2004 than in February 2008, an indication that the cruise track intersected Agulhas rings numerous in this region closer to their centres during the first sampling. Of these eddies, the southernmost one centred at $\sim 39^{\circ} \mathrm{S}$ (Fig.2a) has a very homogenized core of $\sim 12.5^{\circ} \mathrm{C}$ from about $200 \mathrm{~m}$ to $600 \mathrm{~m}$, yet capped by warmer water at the time of the cruise. Gladyshev et al. (2008) showed that this eddy is the product of an Agulhas ring subdivision, and that it spent about 10 months in the SAZ where its saline core water experienced deep winter convection, before it returned to the STZ. Figure $2 b$ reveals another example of such a cooled eddy at $43^{\circ} 20^{\prime} \mathrm{S}$, this time in the SAZ. A backtracking of this structure by altimetry also revealed that it detached from the Agulhas Retroflection about 9 months before being observed, and spent the winter months in the SAZ. It had a $500 \mathrm{~m}$ deep homogeneous core of $\sim 12^{\circ} \mathrm{C}$, also capped by a seasonal thermocline when sampled.

b) Mesoscale-related deep SML south of Africa 
The above observations from the GoodHope CTD lines point to the great mesoscale variability of the STZ and SAZ in this region, with likely effects in terms of SML depths. Although the two examples of convected eddies in Figures 2a,b are not associated with deep SML, they suggest that cases of deep ( 400 m) SML should be expected in the winter ARGO profiles. This is indeed the case, as illustrated in Figure 4a which shows density profiles from two cycles of an ARGO float 20 days apart at $\sim 44^{\circ} \mathrm{S}-16^{\circ} \mathrm{E}$, in late April 2006. In this case, the SML depth was $390 \mathrm{~m}$, and the SML hydrographic characteristics were $\theta \sim 13^{\circ} \mathrm{C}$, and $\mathrm{S}=35.25$. Superimposing float position onto concomitant AVISO $^{1}$ sea surface height map (Fig.4b) reveals that the float sampled the homogeneous core of an anticyclonic eddy detached from the Agulhas Return Current, as was also the case for other examples of deep homogenized profiles. Figure 5 gives the locations of all ARGO profiles having a SML thicker than $250 \mathrm{~m}$, with the ARGO-inferred front tracks superimposed. They are indeed found almost exclusively in the STZ and SAZ. A comparison with weekly AVISO sea surface height fields revealed that those from the STZ are associated with either Agulhas rings (in the Cape Basin) or meanders of the Agulhas Return Current. Those from the SAZ are mostly found in the approximate longitude band $10^{\circ} \mathrm{E}-20^{\circ} \mathrm{E}$. They are representative of Agulhas rings (Dencausse et al., 2010) or eddies (Lutjeharms and Valentine, 1988) that enter the SAZ, where they experience winter convection deeper than in the STZ. Their longitude span approximately matches the $12^{\circ} \mathrm{E}-23^{\circ} \mathrm{E}$ band where Dencausse et al. (2011), using altimetric sea surface height data, observed an interruption of the STF associated with meridional mesoscale exchanges. The locations of deep SML observations in Figure 5 therefore indirectly confirm the existence of such a longitudinally well-defined window of exchange between the STZ and SAZ south of Africa. Also noteworthy in Figure 5 is the relative grouping of thick SML positions southeast of the Agulhas Ridge, where Agulhas rings have been observed to stall

\footnotetext{
${ }^{1}$ AVISO : Archiving, Validation and Interpretation of Satellite Oceanographic data base (http://www.aviso.oceanobs.com/duacs/). The AVISO data base also provided surface geostrophic velocities for the estimation of the SML heat budget (Section 4).
} 
before crossing the bathymetry (Arhan et al., 1999), a behaviour favouring their core modification through heat loss to the atmosphere and mixing with subantarctic water. Farther east at $45^{\circ} \mathrm{S}-50^{\circ} \mathrm{S} / 30^{\circ} \mathrm{E}-32^{\circ} \mathrm{E}$, three deep SML samplings likely signal another region of high mesoscale activity at the South-West Indian Ridge (Ansorge et al., 2006), where observations of anticyclones containing cooled Subantarctic Surface Water have been made (Ansorge and Lutjeharms, 2005).

Processes leading to deep convection in eddy cores in the SAZ are not yet fully understood. Measuring the heat losses to the atmosphere over eddies of subtropical origin observed in the SAZ, Rouault and Lutjeharms (2000) found values as high as $500 \mathrm{~W} \mathrm{~m}^{-2}$ for the latent heat flux and $350 \mathrm{~W} \mathrm{~m}^{-2}$ for the sensible heat flux. Such losses, however, might not be sufficient to explain observed temperature drops up to $5^{\circ} \mathrm{C}$, suggesting some mixing with cool and fresh Subantarctic Surface Water (Arhan et al., 1999). It is most likely that high salinity of the initial subtropical core waters play a role in the destabilization and deepening of the SML in these structures.

The convected eddy at $43^{\circ} 20^{\prime} \mathrm{S}$ in Figure $2 \mathrm{~b}$ also draws attention to the exact definition of the zones $(\mathrm{STZ}, \mathrm{SAZ}, \ldots)$ based on the $\mathrm{DH}_{0 / 1500}$ values of the ARGO profiles, that we introduced above. Its $\mathrm{DH}_{0 / 1500}$ value of 1.7 dyn $\mathrm{m}$ (lower panel) is well above that of the STF, although the structure is located in the SAZ. Similarly, water from the PFZ was apparently advected northward to $\sim 42^{\circ} \mathrm{S}$ by this eddy, which, if sampled by an ARGO float, would result in a $\mathrm{DH}_{0 / 1500}$ value typical of the PFZ. This eddy-dependant interpretation of the four zonal domains defined above should be kept in mind when analyzing the results.

c) The annual cycle of SML properties

In Figure 6a,b,c,d are displayed the annual cycles of the SML properties, namely, potential temperature, salinity, potential density and SML depth, in the 4 above-defined 
zones. The first three parameters are averages over the SML height. For each parameter are shown monthly averages and monthly more probable values (or modes).

Both temperature and salinity panels (Fig.6a,b) exhibit the pronounced gap separating the STZ from the SAZ (5 to $7^{\circ} \mathrm{C}$, and $\left.\sim 1 \mathrm{psu}\right)$. The temperature curves (monthly averages) all exhibit the expected seasonal cycle (a maximum in February-March and a minimum in September-November). There is practically no salinity seasonal variation in the STZ. In all ACC zones the salinity cycle shows a maximum in late winter/spring, and minimum values in March to May. The similarity of the salinity seasonal cycle in the AZ and PFZ was to be expected, as the latter is fed from the south by Antarctic Surface Water crossing the PF in the Ekman layer (Fig.2). The observed cycle matches previous descriptions by Read and Pollard (1993), and by Park et al. (1998a) at the Kerfix station southwest of the Kerguelen islands. Chaigneau et al. (2004), analyzing data south of Tasmania, and Dong et al. (2008) from circumpolar ARGO data also observed the freshest water in summer in the AZ, and attributed this to sea-ice melting. Observing the same annual cycle for salinity in the SAZ was more unexpected, yet could result from density compensating temperature and salinity gradients across the SAF, which favour northward spreading of near-surface water in the Ekman layer across the front. This particularity, pointed out by Rintoul and Trull (2001) south of Australia, was also observed by Gladyshev et al. (2008) along the GoodHope line. The salinity seasonal cycle itself could result from the shallow summer SML being more influenced by this nearsurface arrival of fresh water than the deeper winter SML. We observe, however, that such seasonal salinity variations were not apparent in the pre-ARGO analysis of the SAZ mixed layer south of Australia by Rintoul and Trull (2001), and even not in the analysis of the northern AZ of that region by Chaigneau et al. (2004).

Figure $6 \mathrm{~b}$ also reveals that the SML salinities are lowest in the PFZ, the reflect of their southward increase in the AZ and at the SBy (Fig.2). This feature, which is absent from 
meridional SML salinity distributions at neighbouring longitudes $\left(30^{\circ} \mathrm{E}, 62^{\circ} \mathrm{E}\right.$ : Park et al., 1998b), may be interpreted from the plate of salinity at $50 \mathrm{~m}$ depth in the WOCE Southern Ocean hydrographic atlas (Orsi and Whitworth, 2005). This plate shows that a northeastward eastern exit from the Weddell Sea, relatively saline $(\mathrm{S}>34.0)$ at $50 \mathrm{~m}$ depth, intersects the Greenwich meridian (and the GoodHope line) south of $\sim 53^{\circ} \mathrm{S}$, making the near-surface salinities higher in the AZ than in the PFZ.

The variations of potential density (Fig.6c) all exhibit a classical and well-defined seasonal cycle with winter (summer) maximum (minimum) values clearly dictated by temperature variations. The variations of the monthly mean SML depths (Fig.6d) also all exhibit the classical winter deepening, from $\sim 100 \mathrm{~m}$ in the STZ to $\sim 140 \mathrm{~m}$ in the three ACC zones.

Paying attention to the mode values of the same parameters (continuous lines in Figure 6), we observe that in some frontal zones these are shifted relative to the mean values. This occurs, notably, for temperature in the SAZ and for salinity in the STZ and SAZ. The most probable values tend to be higher (lower) than the monthly mean values in the STZ (SAZ). This reflects asymmetric statistical distributions of the two parameters, and mutual influences of the two frontal zones. As an illustration, Figure 7a shows the statistical distributions of SML salinities in each zone. The STZ distribution is strongly skewed toward low values, a sign that ARGO profiles with $\mathrm{DH}_{0 / 1500}$ values exceeding that of the STF were influenced by SAZ characteristics $(\mathrm{S}<35.0)$, either through northward detachment, and mixing, of subantarctic water, or through southward shedding of Agulhas rings in the SAZ. The SAZ salinity distribution is itself skewed toward high values, with a significant fraction of profiles even exceeding the nominal STF 35.0 value. The wide spreading of the SAZ salinity distribution, from values typical of the Antarctic Surface Water $(S<34.0)$ to values characteristic of the subtropical domain $(\mathrm{S} \sim 35.5)$ illustrates the transitional character of the 
SAZ subject to strong influences from both sides. The winter and summer salinity histograms in the SAZ are themselves widespread, a confirmation that the large property range results from mesoscale rather than seasonal variations.

Histograms of SML depths (Fig.7b) in the STZ show little seasonal variations of their most probable values $(30-50 \mathrm{~m})$, yet the winter distribution is more skewed toward high values. In particular, the expanded views of the distribution tails in Figure $7 \mathrm{~b}$ show that nearly all SML depths in excess of $250 \mathrm{~m}$ are observed in winter, a likely indication of deep convection in eddies like the one at $39^{\circ} 30^{\prime} \mathrm{S}$ in Figure 2a. The SAZ distribution of SML depths also exhibits such high winter values, also as expected from Figure $2 b$ and Figure 5. Finally, the winter and summer mode values of the SML depth in all three zones of the ACC (Fig.7b) confirm the pronounced winter deepening also visible from Figure 6d. In the AZ, the well documented winter deepening of the SML (e.g., Park et al, 1998a), is related to the erosion of the layer of Antarctic Surface Water which caps the Winter Water in summer. The dominant reason for the winter deepening in the PFZ and SAZ - winter heat losses to the atmosphere or northward Ekman advection of cold water - is uncertain.

\section{4) The heat balance equation and computation}

Previous analyses of the heat budget in the Southern Ocean (e.g., Sallée et al. 2006, 2008a; Dong et al., 2007) underlined the dominant roles of air-sea fluxes and Ekman advection in explaining the temporal evolutions of the mixed layer heat content, with geostrophic advection and lateral eddy diffusion also contributing south of western boundary currents. We consider the following heat budget equation with all these terms, but neglecting the fluxes at the base of the SML:

$$
\rho c_{p} h \cdot \frac{\partial T}{\partial t}=-\rho c_{p} h \cdot\left(\mathbf{v}_{\mathbf{g}}+\mathbf{v}_{\mathbf{e}}\right) \nabla T+Q_{n e t}+\rho c_{p} h \cdot \nabla(\kappa \nabla T)
$$


Here $c_{p}$ is the specific heat of sea water, $\rho$ its density, $h$ the mixed layer depth, $v_{g}$ and $\mathrm{v}_{\mathrm{e}}$ the geostrophic and Ekman velocities, $\mathrm{Q}_{\text {net }}$ the net heat flux across the air-sea interface, and $\kappa$ the lateral eddy diffusion coefficient in the SML. In order to evaluate the heat balance in each zone, the computations were first carried out along each ARGO float trajectory with a one month sampling interval, then spatially averaged over each zone. Each term was computed in the way, and using the data, presented below.

a) The mixed layer heat rate of change

We estimated the SML heat rate of change using all ARGO profiles available in the study zone in the period 1 January 2004 to 31 December 2008, and using the same computational procedure as Sallée et al. (2006). ARGO is a pilot programme of the Global Ocean observing System, and ARGO data are made available by the International ARGO Project and the national programmes that contribute to it (http://www.argo.ucsd.edu, http://argo.jcommops.org). The data used here are real time data flagged "good" or "probably good", and were obtained through the Coriolis data centre (http://www.coriolis.eu.org). More specifically, a total of 8715 hydrographic profiles from 244 ARGO floats were used for this study. The main ARGO projects contributing to this set are listed in Table 3, which also gives the number of profiles that were available in each of the four zones defined from the $\mathrm{DH}_{0 / 1500}$ criterion. The highest number of profiles is from the GoodHope project, to which this study is a contribution, and which has made regular float deployments since 2004 along the GoodHope transect represented in Figure 1. The best sampled zone is the STZ (3509 profiles), notably because of longer float residence times in this highly turbulent area. A rapid eastward drift of the floats explains the lower number of profiles in the three ACC zones. Of these, the $\mathrm{AZ}$ is the least sampled one, partly because of the relatively shallow $(<2000 \mathrm{~m})$ bathymetry of 
the Mid-Atlantic and Southwest Indian ridges, that caused premature float working interruptions. The heat rate of change in the SML was computed as:

$$
\rho c_{p}\left[\int_{h_{m}}^{0} T(z) d z\right]_{t_{1}}^{t_{2}} \text { with } h_{m}=\max \left(h_{1}, h_{2}\right)
$$

where $\mathrm{h} 1$ and $\mathrm{h} 2$ are the SML depths of two ARGO profiles of the same float in the same zone, and separated by 30 days (that is, 3 ARGO cycles apart), in order to filter out high frequency variations of heat content.

\section{b) The geostrophic advection term}

The geostrophic advection term of equation (1) was estimated using altimetric absolute geostrophic velocities provided by the Archiving, Validation and Interpretation of Satellite Oceanographic data base (AVISO; see Table 4 for the origins and resolution characteristics of the data and reanalysis products used). Temperature $\mathrm{T}$ was extracted from the remote sensing SST fields of satellite AMSR-E (Table 4), and h was the average of the SML depths at the two 30-days separated ARGO profiles used for the computation.

Since SML heat content variations were computed along float trajectories over intervals of 30 days, the geostrophic advection term (as all forcing terms) was first estimated for each 10-day float cycle, and then averaged over the three cycles separating the dates of heat content calculations. Separating the calculation of the forcing terms in three portions presents the advantage (not so obvious for the geostrophic term, though) to capture weather scale variability of the Ekman transport, and air-sea turbulent and radiative fluxes.

c) The Ekman term and net air-sea heat fluxes

The Ekman term was computed also using AMSR-E sea surface temperature data, and QuikSCAT daily wind product also providing the wind stress $\tau$ at the sea surface, and from which the Ekman volume transport is readily obtained as $\mathbf{T e}=-(\mathbf{k} \times \tau) / \rho f$, with $\mathrm{f}$ being the Coriolis parameter (Table 4); 
The net air-sea flux was computed as the sum of turbulent and radiative heat fluxes. Turbulent fluxes were obtained from the OAflux Project (Yu et al., 2008) of the Woods Hole Oceanographic Institution (Table 4). This project develops a methodology for global estimates of air-sea fluxes, a so-called synthesis, which combines measured meteorological variables with various reanalyses in a manner that minimizes the misfit between data and reanalyses. The variables (e.g., sea surface temperature, wind speed,...) issued from the synthesis are used to compute turbulent air-sea fluxes with state-of-the-art bulk flux parameterization (e.g., Fairall et al., 2003). We chose the OAflux product because it results from a global analysis consistent with in situ observations, and because a comparison with turbulent fluxes in situ measurements during the 2008 GoodHope cruise was in favour of OAflux (J. Sachs, personnal communication).

The radiative fluxes come from the International Satellite Cloud Climatology Project (ISCCP), and are distributed (and recommended for use) with the OAflux data. In the Southern Ocean, meteorological variables unmeasured by remote sensing are poorly sampled (water vapour, sea surface air temperature). In order to get a visual estimate of errors arising from this undersampling, these air-sea heat flux products are compared with two others in Section $5 \mathrm{~d}$ below.

\section{d) Turbulent diffusion}

The horizontal eddy diffusivities used for the computation of the heat lateral diffusion term are annual climatological values estimated by Sallée et al. (2008b) from a statistical analysis of surface drifter observations. The domain of study exhibits great variations of the diffusion coefficient, from the Agulhas retroflection and Agulhas Return Current areas, where $\kappa$ values in excess of $10^{4} \mathrm{~m}^{2} \mathrm{~s}^{-1}$ were found by Sallée et al. (2008b), to the ACC domain showing values usually below $500 \mathrm{~m}^{2} \mathrm{~s}^{-1}$. The diffusivities, provided in bins of $5^{\circ}$ longitude $\mathrm{x}$ $1^{\circ}$ latitude (courtesy J.B. Sallée), were used in combination with a monthly climatology of sea 
surface temperature using the AMSR-E data (Table 4). Monthly averaged temperatures were themselves smoothed using a Gaussian filter with a $200 \mathrm{~km}$ standard deviation to make them consistent with the mesoscale eddy diffusivities.

\section{5) The annual cycle of the Surface Mixed Layer heat budget}

a) Yearly averages

The heat content rates of change in the four studied zones are displayed in Figure 8, along with the four terms at the right-hand side of equation 1 (Fig.8a), and with the sum of these four terms (Fig.8b). Uncertainties in Figure $8 \mathrm{~b}$ were computed assuming that the number of independent elementary heat budget estimates was one fifth of the number of ARGO profiles for each month, following our choice to compute the elementary budgets over 30 days intervals (or four successive float profiles). The annual averages of all terms, computed from the monthly values, are reported in Table 5. Uncertainties (in the first two columns) were computed assuming four independent monthly estimates per year, considering that interannual variations occur at a seasonal time scale. First examining these annual means, the ARGO-inferred heat content variations (first column) are negative in all zones, yet not significantly, or hardly, different from zero. The sum of the forcing terms (second column) is only statistically significant in the STZ. Differences between the two columns do not exceed $36 \mathrm{~W} \mathrm{~m}^{-2}$, an acceptable value given the uncertainties. The averaged residuals of equation (1) were also estimated directly from the elementary budget computations in 30 days intervals

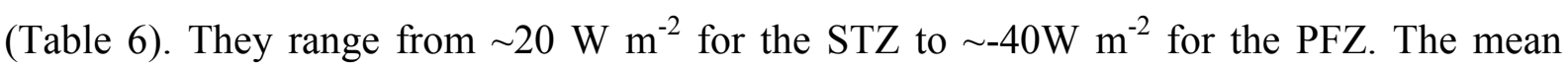
residuals thus computed are nearly identical to the differences between columns 1 and 2 of Table 5, the slight differences resulting from an equal weighting of each month in one case, not in the other.

On annual average, the STZ receives heat through geostrophic advection (Table 5), and is cooled by the three other forcing terms. The dominant heating factor in the SAZ is eddy 
diffusion, approximately compensated by the sum of Ekman and geostrophic advection. The PFZ and AZ are characterized by weak geostrophic advection and eddy diffusion, a likely consequence of relatively stable bounding fronts. In these two zones, cooling by Ekman advection and surface warming are the dominant terms.

\section{b) Annual cycles}

Regarding seasonal variations (Fig.8a,b), a well-defined annual cycle dominates the heat content rate of change in all zones. Winter cooling is at a maximum in the STZ where it reaches $200 \mathrm{Wm}^{-2}$ in July, and peaks around $100 \mathrm{Wm}^{-2}$ in the other zones. The maximum summer warming (December/January) does not exceed $100 \mathrm{Wm}^{-2}$ in any of the four zones. In all zones the seasonal cycle of the heat content rate of change is mostly controlled by air-sea fluxes (Sallée et al., 2006; Dong et al., 2007) which themselves exhibit crest-to-trough variations of about $200 \mathrm{Wm}^{-2}$. Summer and winter maps of $\mathrm{Q}_{\text {net }}$ (Fig.9) reveal that the ocean gains heat from the atmosphere in nearly the whole region in summer, the only spatially limited exception being the core of the Agulhas Current retroflection, and loses heat everywhere in winter, as suggested by the air-sea fluxes of Figure $8 \mathrm{a}$. The signature of the Agulhas Retroflection, visible through enhanced heat losses, stands out more clearly during winter than during summer. This certainly results from diminished sea surface temperature differences between the Agulhas and surrounding waters in summer, when the whole region is capped by a seasonal thermocline. The summer and winter maps of net air-sea fluxes in Figure 9 are qualitatively very similar to previous distributions north of $41^{\circ} \mathrm{S}$ by Walker and Mey (1988), yet with more pronounced winter heat losses in the core of the retroflection ( $270 \mathrm{~W} \mathrm{~m}^{-2}$ as compared with $-175 \mathrm{~W} \mathrm{~m}^{-2}$ ). Averaging the net heat fluxes throughout the year $\left(3^{\text {rd }}\right.$ column of Table 5) confirms that the ocean loses heat to the atmosphere on average north of the STF, but gains heat from it south of this front, particularly in the PFZ and AZ. 
In the STZ, the second important term after the air-sea fluxes is lateral geostrophic advection which is year-round positive, in keeping with the idea that the water brought into the region by the Agulhas Current is warmer than the water extracted from it by the Agulhas Return Current. Geostrophic advective heat gain is higher in winter, because near surface temperature contrasts are not blurred by the all-covering seasonal thermocline. Eddy diffusion, the result of the penetration of cold core eddies from the SAZ, and Ekman advection, also have negative contributions.

The STZ winter and summer mixed layer heat balances are different, as illustrated by July and December. In winter (July), heating due to geostrophic advection $\left(+50 \mathrm{Wm}^{-2}\right)$ is cancelled out by Ekman cooling, and eddy diffusion amplifies air-sea heat flux cooling of the SML. In summer (December), lateral geostrophic advection nearly vanishes, and both Ekman advection and eddy diffusion cooling contributions $\left(-50 \mathrm{Wm}^{-2}\right.$ overall) tend to mitigate air-sea flux heating.

The SAZ is characterized by year-round strong positive heat diffusion, culminating at $\sim 170 \mathrm{Wm}^{-2}$ in late winter. This undoubtedly reflects numerous southward penetrations of warm eddies into this zone, as documented by Lutjeharms and Valentine (1988), by Dencausse et al. (2010), and indirectly in Figure 5 above. Mixing of the warm waters of these eddies with the ambient subantarctic waters is likely to be a major contributor to the high heat diffusion term estimated here. The sign reversal of this term relative to the STZ is typical of diffusion across a front, yet a pronounced asymmetry in amplitude is noticeable. Part of this asymmetry might be attributed to the fact that mesoscale structures contributing to these eddy diffusive terms in the STZ and SAZ do not form at the STF itself, but at the Agulhas Front associated with the Agulhas Return Current, located a few degrees north of the STF. For a closer examination of the lateral eddy diffusion term, we show in Figure 10 a map of annually averaged heat budget residuals obtained when omitting the lateral diffusion term in equation 
(1) (Fig.10a), and a map of this term computed from the diffusivities of Sallée et al. (2008b) (Fig.10b). Although the residual map displays more small scale structure than that of the diffusion term, both distributions show enhanced values in and around the Agulhas Retroflection, and a tendency for compensation of the residuals is apparent in the latter. The geographical distribution of the diffusive term exhibits the expected sign reversal across the STF, and shows flux intensities comparable to those of the residuals.

The SAZ panel of Figure 8a illustrates another remarkable forcing feature, namely, the near stability (here at $-50 /-100 \mathrm{Wm}^{-2}$ ) of the Ekman advection term. To better analyze this feature, we show the seasonal variations of wind speed and Ekman advection term along $20^{\circ} \mathrm{E}$ in Figure 11a,b, as directly computed from the gridded QuikSCAT and AMSR-E products (Table 4). The wind monthly climatology at $20^{\circ} \mathrm{E}$ does present well-defined seasonal variations, yet of limited amplitudes, with the latitudinal maximum (at $50^{\circ} \mathrm{S}-55^{\circ} \mathrm{S}$ ) ranging from $\sim 10 \mathrm{~m} / \mathrm{s}$ in summer to $\sim 12 \mathrm{~m} / \mathrm{s}$ in winter. The heat budget Ekman advection term (Fig.11b) is negative everywhere in the ACC, but only significant north of the $\mathrm{PF}$ at $\sim 53^{\circ} \mathrm{S}$. Its seasonal variations are pronounced at the front latitudes, particularly at $44^{\circ} \mathrm{S}$ (SAF) and $40^{\circ} \mathrm{S}$ (STF), with values lower in summer when the cross frontal temperature gradients are dimmed by the seasonal thermocline, than in winter. This, and the strongly attenuated variations in between fronts, point to a dominant effect of temperature gradients in the Ekman term variability, and explain the year-round stability in the curves of Figure 8a, which represent intra-zone time variations not influenced by cross-frontal transfers.

Incidentally, Figure $11 \mathrm{a}$ exhibits a wind speed maximum at $\sim 38^{\circ} \mathrm{S}$ during winter, that reflects the response of the atmospheric boundary layer to the high sea surface temperatures of the Agulhas Current retroflection (O’Neill et al., 2005). The wind perturbation is hardly visible during summer, and non-existent at longitudes which do not intersect the Agulhas Retroflection (not shown). 
Returning to the SAZ panel of Figure $8 \mathrm{a}$, the last contribution to the heat budget is the geostrophic advection term which, rather surprisingly, exhibits a seasonal cycle mimicking that of the air-sea heat fluxes. The significant winter negative value means that geostrophic advection in the SAZ evacuates eastward part of the heat brought to the zone through diffusion. In this zone also, winter and summer heat balance regimes are much contrasted. In winter, eddy induced heat input from the north is the only positive term acting against the cooling tendencies of all other forcing terms. In summer, on the other hand, Ekman advection is the only negative term, mitigating the warming tendencies of all other processes.

As was already apparent in yearly averages (Table 5), the SML heat budget in the PFZ differs importantly from the SAZ budget. The eddy diffusion term, which was dominant in the SAZ, nearly vanishes in the PFZ, and the geostrophic advection term is also weak. Ekman advection, which is again nearly constant throughout the year $\left(-50 \mathrm{Wm}^{-2}\right)$, and air-sea fluxes, are the main forcing terms. Summer heat gain from the atmosphere is higher than in the other zones, reaching $150 \mathrm{Wm}^{-2}$ in December. The sum of these two main terms accounts for a SML warming rate of $\sim 100 \mathrm{Wm}^{-2}$ in summer, and cooling rate of $-100 \mathrm{Wm}^{-2}$ in winter, yet partly counterbalanced by a positive contribution of geostrophic advection in this season.

The AZ mixed layer heat balance resembles that of the PFZ, the only difference being a weaker Ekman advection, negligible in summer and highest $\left(-40 \mathrm{Wm}^{-2}\right)$ in October.

\section{c) Uncertainties}

Monthly residuals in Figure $8 \mathrm{~b}$ are generally within the plus/minus uncertainty bars computed for each curve. As mentioned above, these uncertainties on the monthly values include the effects of interannual variability in addition to errors. The errors themselves can be attributed to the data, computation procedures, or to missing terms. Of these factors, Dong et al. (2007) underlined that air-sea fluxes, due to the scarcity of in situ measurements in the Southern Ocean, are expected to be the largest contributors to the SML heat budget 
imbalances. For a rough evaluation of the uncertainty associated with surface heat fluxes, we show in Figure 12 a comparison between three products, namely, the OAflux and ISCCP fluxes used in Figure 8, the NCEP2 ${ }^{2}$ fluxes and the ERA-Interim ${ }^{3}$ re-analysis from the European Centre for Medium Range Weather Forecasts (ECMWF). The comparison being done for each zone, latent and sensible flux products were found to agree well in the STZ, with differences around $5 \mathrm{~W} \mathrm{~m}^{-2}$. In the PFZ (Fig.12), where differences are the largest, radiative NCEP2 fluxes exceed those of the two other products by $\sim 30 \mathrm{~W} \mathrm{~m}^{-2}$ in summer (Fig.12a). This difference is amplified by differences in turbulent fluxes (Fig.12b,c), so that net NCEP2 fluxes finally exceed OA+ISCCP fluxes by $\sim 40 \mathrm{~W} \mathrm{~m}^{-2}$ (Fig.12d,e) on average; a difference comparable in magnitude to the average residual in the PFZ, and to the Ekman advection term in the same zone. The difference with ERA-Interim net fluxes shows the opposite sign, and a slightly larger magnitude of $\sim 60 \mathrm{~W} \mathrm{~m}^{-2}$. Although using ERA-Interim fluxes would have reduced heat budget residuals in the PFZ, the comparison was not meant to choose one or the other product (we noted above that direct comparisons with in situ measurements favoured the OA turbulent fluxes), but to get an idea of the uncertainty associated with surface fluxes.

Ascribing uncertainties to the lateral diffusion term is also difficult. One source of error arises from using an annual climatological mean for diffusivity. Sallée et al. (2008b) suggested that the variability of diffusivity at seasonal time scales is about $10-15$ percent, and Sallée et al. (2008a) noted that the annual climatological mean should be similar to the winter mean. Lateral diffusion uncertainties are likely to be significant only in the SAZ and, assuming a summer reduction of 15 percent relative to the winter value, this would reduce the observed summer imbalance of $\sim 70 \mathrm{Wm}^{-2}$ by about $20 \mathrm{Wm}^{-2}$.

\footnotetext{
${ }^{2}$ NCEP2 : NCEP re-analysis 2 data are provided by the NOAA/OAR/ESRL PSD, Boulder, Colorado, USA, from their web site at http://www.esrl.noaa.gov/psd/.

${ }^{3}$ ERA-Interim : The ERA-Interim re-analysis data of the European Centre for Medium Range Weather Forecasts

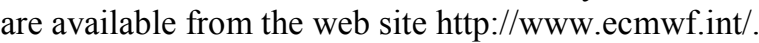


Other possibly significant contributions to imbalances are the omitted fluxes at the base of the mixed layer, whose computations are delicate. Dong et al. (2007) estimate that, in general, the radiative fluxes are less than $20 \mathrm{Wm}^{-2}$, which is relatively small compared to the uncertainty of surface heat fluxes in the Southern Ocean. They note, however, that entrainment of water from below the base of the SML results in a cooling contribution in fall and winter. Estimating this term from the turbulent kinetic energy balance and assuming that it vanishes during the detraining period, they find cooling rate peaks up to $\sim-0.2^{\circ} \mathrm{Cs}^{-1}$ (or $\sim 80$ $\mathrm{Wm}^{-2}$ assuming a $100 \mathrm{~m}$ deep SML) in the Southern Ocean Atlantic sector, between $40^{\circ} \mathrm{S}$ and $60^{\circ} \mathrm{S}$. This makes this omitted term another possible source of imbalance.

Errors on the advective terms, finally, should be lower than those of surface heat fluxes, given the comparatively accurate sea surface temperature and multi-satellite altimetric products, and the well resolved QuikSCAT wind data. As mentioned above, we estimated the forcing terms at a 10-day temporal resolution in order to have the computations include weather scale variability. The Ekman layer was assumed to be everywhere shallower than the SML. Although this may not be the case during summer in the STZ (Fig.6d), the corresponding low values of Ekman advection (Fig.8a) make this defect a negligible one.

Overall, the computed imbalances between the observed heat rate of change and forcing terms (Table 6) fall within the uncertainty range of $50-100 \mathrm{Wm}^{-2}$ that can be inferred from the above discussion, and roughly match the error bars deduced from standard deviation computations. The differences between surface heat flux products $\left(\sim 50 \mathrm{Wm}^{-2}\right.$ on average according to our Figure 12, and up to more than $100 \mathrm{Wm}^{-2}$ according to Dong et al., 2007) likely dominate these errors. Table 6 shows that, except for the STZ, residuals are negative, that is, the sum of the forcing terms exceeds the heat rate of change. Disregarding the heat surface flux uncertainty, we observe that several factors of imbalance, if possibly corrected, would bring the forcing terms closer to the observed heat rate of change. In the SAZ we 
mentioned above that a summer reduction of the lateral diffusion term would better close the budget. Similarly, the observed highest negative imbalances in the PFZ and AZ might be related to wind stress curl-induced upwelling in these areas, which likely favours upward entrainment of cold water at the SML base.

\section{6) Summary and discussion}

Although the GoodHope hydrographic transect does not intersect the Agulhas Current nor the Agulhas Return Current, Figure 2 nevertheless illustrates the transitional character of the studied region, from a regime of intense mesoscale activity influenced by the subtropical western boundary current, to the ACC regime. Because the two represented hydrographic samplings were carried out at times when a seasonal thermocline was present (though in a nascent form in Figure 2a), the general southward deepening of the SML, up to $150 \mathrm{~m}$ depth, is relatively smooth in both realizations. That this is not always the case, however, is suggested by the presence of Agulhas rings with deep homogenized cores in the STZ and SAZ, and was confirmed by SML as deep as $\sim 400 \mathrm{~m}$ in some ARGO profiles (Fig.4). Such deep SML always form within original South Indian Central Water, either in the Agulhas retroflection loop itself (Gordon et al., 1987), or in Agulhas rings or eddies whose paths penetrate the SAZ.

The role of the SAZ as a transitional zone between the subtropical domain and the ACC is particularly striking south of Africa, where this zone is much influenced from the northern and southern adjacent domains. Agulhas rings and eddies crossing the STF southward in this region, as illustrated from figure $2 \mathrm{~b}$ and previously described (Lutjeharms and Valentine, 1988), are certainly a major factor for conveying subtropical characteristics into the SAZ. Such transfers, more generally, are favoured by eddy-induced discontinuities in the STF at $\sim 12^{\circ} \mathrm{E}-23^{\circ} \mathrm{E}$, that were studied by Dencausse et al. (2011). It is remarkable that this 
band of longitude is the approximate location where deep SML occurrences marking anticyclones of subtropical origin were observed in the SAZ, an indication of the efficiency of this exchange window. As seen at other longitudes, the northward Ekman drift across the near-surface density compensated SAF must also be efficient in injecting cold and fresh surface water from the south in the SAZ. In Figure 2a, fresher waters above $\sim 200 \mathrm{~m}$ in the SAZ might be a signature of this process. Figure $2 b$, however, illustrates an additional mechanism for northward water transfer across the SAZ in this region. As mentioned above, the cooled Agulhas ring at $43^{\circ} 20^{\prime} \mathrm{S}$ in February 2008 was adjacent to the SAF and apparently entrained northward (to $\sim 42^{\circ} \mathrm{S}$ from Figure $2 \mathrm{~b}$ ) water from the PFZ into the SAZ. These entries from north and south give the SAZ waters south of Africa a broad range of properties and make this zone the real transition, and a sort of melting area, between the subtropics and ACC domains. This stands out particularly in Figure $2 b$, as an alternation of water parcels from the STZ and PFZ occupying the SAZ, and in Figure 7a, from a 2 psu-wide range of salinities in the SAZ panel.

Meridional evolution and pronounced change of regime across the SAF are also evident when analyzing the heat budget in each zone. While net air-sea heat fluxes dictate the heat budget variability in the whole region, in the STZ heat is mostly brought throughout the year by lateral geostrophic advection, as expected at the poleward end of a western boundary current. In the SAZ, the dominant heat contribution by lateral diffusion reflects the role of Agulhas rings and eddies discussed above. Proceeding southward across the SAF, the lateral geostrophic advection and diffusion terms nearly vanish, leaving Ekman cooling and seasondependant net air-sea fluxes as the dominant contributors to the heat budget.

Sallée et al. (2006) also found positive heat diffusion in the SAZ downstream of the Agulhas Retroflection at $20^{\circ} \mathrm{E}-40^{\circ} \mathrm{E}$ (not exceeding $\sim 20 \mathrm{Wm}^{-2}$, though) and farther east to $60^{\circ} \mathrm{E}$, where this term reverses. They underlined that such positive heat diffusion, by 
counterbalancing cooling by Ekman advection and air-sea fluxes, tends to stabilize the SML west of $60^{\circ} \mathrm{E}$. On the other hand, they regarded its destabilizing tendency east of this longitude as a preconditioning to deep convection and Subantarctic Mode Water formation farther east in the Indian Ocean. This study confirms the stabilizing role of eddy diffusion in the SAZ heat budget south of Africa, yet it also shows that deep convection (up to $\sim 400 \mathrm{~m}$ ) can occur in parcels of South Indian Central Water present in the SAZ in this region (Fig.4,5). The cause for this certainly resides in the warm South Indian Central Water being also very saline so that, once its temperature has decreased through intense heat loss to the atmosphere, the destabilizing tendencies of its salinity become dominant and may lead to deep convection after a few months. As salinity is inevitably diffused southward with temperature across the STF, its destabilizing potential is necessarily associated with the stabilizing potential of temperature. The observation of convected eddies reveals that, when confined in such structures, the South Indian Central Water experiences cooling at a rate which leads the salinity effect to overcome that of temperature in less than a year time. Outside the eddies however, where subtropical properties are more diluted and heat loss slower, a longer time scale might be required for the salinity effect to overcome the temperature one. If this was correct, southward salinity diffusion expected to be associated to temperature diffusion south of Africa would constitute a first preconditioning to downstream remote deep convection, subject to reinforcement by the temperature effect at $60^{\circ} \mathrm{E}$ that Sallée et al.(2006) underlined. The present lack of data appropriate to assess salinity budgets similar to heat budgets makes it difficult to confirm this hypothesis.

\section{Acknowledgements:}

This contribution to the CLIVAR/GoodHope program was supported by the IFREMER program "Circulation Océanique”, by INSU (Institut National des Sciences de l'Univers), the CNRS (Centre National de la Recherche Scientifique), and by the Université de Bretagne 
Occidentale. V. Faure's contribution was done while a postdoctorate at the Laboratoire de Physique des Océans, supported by a grant from the CNRS. S. Gladyshev's participation benefited by a contract for bilateral cooperation between the CNRS and the Russian Academy of Sciences. We are thankful to J.B. Sallée for providing us with his surface diffusivity values, and to C. Messager for useful discussions on the air-sea heat fluxes. The aid of A. Prigent in the preparation of some Figures is acknowledged. 


\section{References:}

Ansorge I.J., Lutjeharms J.R.E (2005) Direct observations of eddy turbulence at a ridge in the Southern Ocean. Geophys Res Lett, 32, L14603, doi:10.1029/2005GL022588.

Ansorge I.J., Lutjeharms J.R.E, Swart N.C., Durgadoo J.V. (2006) Observational evidence for a cross frontal heat pump in the Southern Ocean. Geophys Res Lett, 33, L19601, doi:10.1029/2006GL026174.

Arhan M., Mercier H., Lutjeharms J.R.E. (1999) The disparate evolution of three Agulhas rings in the South Atlantic Ocean. J Geophys Res, 104, 20987-21005.

Belkin I.M., Gordon A.L. (1996) Southern ocean fronts from the Greenwich meridian to Tasmania. J Geophys Res, 101, 3675-3696.

Branellec P., Arhan M., Speich S. (2010) Projet GoodHope - Campagne BONUS/GoodHope, Rapport de données CTD-O 2 . IFREMER internal report OPS/LPO/10-02, 284p.

Chaigneau A., Morrow R.A., Rintoul S.R. (2004) Seasonal and interannual evolution of the mixed layer in the Antarctic Zone south of Tasmania. Deep-Sea Res I, 51, 2047-2072.

Dencausse G., Arhan M., Speich S. (2010) Routes of Agulhas rings in the southeastern Cape Basin. Deep-Sea Res I, 57, 1406-1421, doi: 10.1016/j.dsr.2010.07.008.

Dencausse G., Arhan M., Speich S. (2011) Is there a continuous Subtropical Front south of Africa? J Geophys Res, 116, C02027, doi:10.1029/2010JC006587.

Dong S., Gille S.T., Sprintall J. (2007) An assessment of the Southern Ocean mixed layer heat budget. J Clim, 20, 4425-4442.

Dong S., Sprintall J., Gille S.T., Talley L. (2008) Southern Ocean mixed-layer depth from ARGO float profiles. J Geophys Res, 113, doi: 10.1029/2006JC004051.

Fairall C., Bradley E., Hare J., Grachev A., Edson J. (2003) Bulk parameterization of air-sea fluxes: Updates and verification for the COARE algorithm. J Clim, 16, 571-591. 
Gladyshev S., Arhan M., Sokov A., Speich S. (2008) A hydrographic section from South africa to the southern limit of the Antarctic Circumpolar Current at the Greenwich meridian, Deep-Sea Res I, 55, 1284-1303.

Gordon A.L., Lutjeharms J.R.E., Gründlingh M.L. (1987) Stratification and circulation at the Agulhas retroflection. Deep-Sea Res, 34, 565-599.

Lee-Thorp A.M., Rouault M., Lutjeharms J.R.E. (1998) Cumulus cloud formation above the Agulhas Current. South African J Science, 94, 351-354.

Legeais J.F., Speich S., arhan M., Ansorge I., Fahrbach E., Garzoli S., Klepikov A. (2005)

The baroclinic transport of the Antarctic Circumpolar Current south of Africa. Geophys Res Lett, 32, L24602, doi:10.1029/2005GL023271.

Lutjeharms J.R.E., Rouault M. (2000) Observations of cloud formation above Agulhas Current intrusions in the Southeast Atlantic. South African J Science, 96, 577-580.

Lutjeharms J.R.E., Valentine H. (1988) Eddies at the subtropical convergence south of Africa. J Phys Oceanogr, 18, 761-774.

McCartney M.S. (1977) Subantarctic mode water. In: Angel M. (ed), A voyage of discovery, Pergamon, New York, pp103-109.

Mey R.D., Walker N.D., Jury M.R. (1990) Surface heat fluxes and marine boundary layer modification in the Agulhas retroflection region. J Geophys Res, 95, 15997-16015.

Olson D.B., Fine R.A., Gordon A.L. (1992) Convective modifications of water masses in the Agulhas. Deep-Sea Res, 39, Suppl.1, S163-S181.

O’Neill L.W., Chelton D.B., Esbensen S.K., Wentz F.J. (2005) High-resolution satellite measurements of the atmospheric boundary layer response to SST variations along the Agulhas Return Current. J Clim, 18, 2706-2723.

Orsi A.H., Whitworth III T., Nowlin W.D. (1995) On the meridional extent and fronts of the Antarctic Circumpolar Current. Deep-Sea Res I, 42, 641-673. 
Orsi A.H., Whitworth III T. (2005) Hydrographic Atlas of the World Ocean Circulation Experiment (WOCE). Volume 1: Southern Ocean. WOCE International Project Office, University of Southampton, Southampton, UK.

Park Y.-H., Charriaud E., Ruiz Pino D., Jeandel C. (1998a) Seasonal and interannual variability of the mixed layer properties and steric height at station KERFIX, southwest of Kerguelen. J Mar Syst, 17, 571-586.

Park Y.-H., Charriaud E., Fieux M. (1998b) Thermohaline structure of the Antarctic Surface Water/Winter Water in the Indian sector of the Southern Ocean. J Mar Syst, 17, 5-23.

Park Y.-H., Charriaud E., Craneguy P. (2001) Fronts, transport and Weddell Gyre at $30^{\circ} \mathrm{E}$ between Africa and Antarctica. J Geophys Res, 106, 2857-2879.

Read J.F., Pollard R.T. (1993) Structure and transport of the Antarctic Circumpolar Current and Agulhas Return Current at 40․ J Geophys Res, 98, 12281-12295.

Rintoul S.R., Trull T.W. (2001) Seasonal evolution of the mixed layer in the Subantarctic Zone south of Australia. J Geophys Res, 106, 31447-31462.

Roether W., Samthein M., Müller T.J., Nellen W., Sahrhage D. (1990) SüdatlantikZircumpolarstrom, reise Nr 11, 3 Oktober 1989- 11 März 1990, Meteor-Ber. 90-2, Univ. Hamburg, Hamburg, Germany, 169pp.

Rouault M., Lutjeharms J.R.E. (2000) Air-sea exchange over an Agulhas eddy at the subtropical convergence. Global Atm Ocean Syst, 7, 125-150.

Sallée J.-B., Wienders N., Speer K., Morrow R. (2006) Formation of subantarctic mode water in the southeastern Indian Ocean. Ocean Dyn, 56, 525-542.

Sallée J.-B., Morrow R., Speer K. (2008a) Eddy heat diffusion and Subantarctic Mode Water formation. Geophys Res Lett, 35, L05607, doi:10.1029/2007GL032827. 
Sallée J.-B., Speer K., Morrow R.,Lumpkin R. (2008b) An estimate of Lagrangian eddy statistics and diffusion in the mixed layer of the Southern Ocean. J Mar Res, 66, 441463.

Sokolov S., Rintoul S.R. (2009) Circumpolar structure and distribution of the Antarctic Circumpolar Current fronts: 1. Mean circumpolar paths. J Geophys Res, 114, C11018, doi:10.1029/2008JC005108.

Walker N.D., Mey R.D. (1988) Ocean/atmosphere heat fluxes within the Agulhas retroflection region. J Geophys Res, 93, 15473-15483.

Whitworth III T., Nowlin W.D. (1987) Water masses and currents of the Southern Ocean at the Greenwich meridian. J Geophys Res, 92, 6462-6476.

Yu L., Jin X., Weller R.A. (2008) Multidecade global flux data sets from the objectively analyzed air-sea fluxes (OAflux) project: Latent and sensible heat fluxes, ocean evaporation, and related surface meteorological variables. OAFlux Project Technical Report OA-2008-01, Woods Hole Oceanographic Institution, Woods Hole, Massachusetts. 


\begin{tabular}{|c|c|c|c|c|c|c|}
\hline Section & AJAX & A12 & $\mathbf{A 2 1}$ & ASV-19 & I6 & I6s \\
\hline Date & Jan 1984 & May-Aug 1992 & Jan-Mar 1990 & Nov 2004 & Feb-Mar 1996 & Feb-Mar 1993 \\
\hline Ship & R/V Knorr & R/V Polar Stern & R/V Meteor & $\begin{array}{c}\text { R/V Ak. S. } \\
\text { Vavilov }\end{array}$ & $\begin{array}{c}\text { N/O Marion } \\
\text { Dufresne }\end{array}$ & $\begin{array}{c}\text { N/O Marion } \\
\text { Dufresne }\end{array}$ \\
\hline $\begin{array}{c}\text { Institution } \\
\text { and Chief } \\
\text { scientist }\end{array}$ & $\begin{array}{l}\text { Texas A\&M } \\
\text { T. Whitworth }\end{array}$ & $\begin{array}{c}\text { A.W.I. } \\
\text { P. Lemke }\end{array}$ & $\begin{array}{l}\text { Univ. Bremen } \\
\text { W. Roether }\end{array}$ & $\begin{array}{l}\text { Shirshov Inst. } \\
\text { Oceanology } \\
\text { S. Gladyshev }\end{array}$ & $\begin{array}{l}\text { LBCM Paris } \\
\text { A. Poisson }\end{array}$ & $\begin{array}{l}\text { LBCM Paris } \\
\text { A. Poisson }\end{array}$ \\
\hline Source & $\begin{array}{l}\text { Whitworth and } \\
\text { Nowlin (1987) }\end{array}$ & http://whpo.ucsd.edu & $\begin{array}{l}\text { Roether et al. } \\
\qquad(1990)\end{array}$ & $\begin{array}{c}\text { Gladyshev et al. } \\
\text { (2008) }\end{array}$ & $\begin{array}{l}\text { Park et al. } \\
\text { (2001) }\end{array}$ & Park et al. (1998b) \\
\hline
\end{tabular}

Table 1: Summary of the hydrographic lines used to associate a value of dynamic height (referenced to 1500 dbar) to each front of the Antarctic Circumpolar Current. Acronyms have the following meanings: A.W.I., Alfred Wegener institute; LBCM, Laboratoire de Biogéochimie et Chimie Marine.

\begin{tabular}{cccc}
\hline Front & $\begin{array}{c}\text { Dynamic height referenced } \\
\text { to 1500 dbar (dyn m) } \\
\text { (South of Africa) }\end{array}$ & $\begin{array}{c}\text { Sokolov and Rintoul (2009) } \\
\text { (Circumpolar) }\end{array}$ & $\begin{array}{c}\text { Sallée et al. (2008a) } \\
\text { (Circumpolar) }\end{array}$ \\
\hline Sub Tropical Front & $1.55 \pm 0.03$ & $1.44 \pm 0.02(\mathrm{SAF}-\mathrm{N})$ & 1.20 \\
Subantarctic Front & $1.29 \pm 0.02$ & $1.23 \pm 0.02(\mathrm{SAF}-\mathrm{M})$ & 0.95 \\
Polar Front & $0.90 \pm 0.02$ & $0.90 \pm 0.01(\mathrm{PF}-\mathrm{N})$ & \\
Southern ACC Front & $0.62 \pm 0.02$ & $0.64 \pm 0.02(\mathrm{SACCF}-\mathrm{N})$ & \\
Southern Boundary & $0.58 \pm 0.01$ & $0.57 \pm 0.01(\mathrm{SACCF}-\mathrm{S})$ & \\
\hline
\end{tabular}

Table 2: First column: Values of dynamic heights $\mathrm{DH}_{0 / 1500}$ used to determine the ACC fronts south of Africa. Second and third column: corresponding values chosen by Sokolov and Rintoul (2009) and Sallée et al. (2008a) in circumpolar studies. 


\begin{tabular}{ccc}
\hline Argo Project & Number of Floats & $\begin{array}{c}\text { Number of } \\
\text { profiles }\end{array}$ \\
\hline Goodhope (Ifremer, France) & 57 & 2960 \\
US Argo (AOML, USA) & 94 & 2613 \\
Argo UK (BODC, United Kingdom) & 37 & 1533 \\
J-Argo (Jamstec, Japan) & 16 & 448 \\
Other & 40 & 1161 \\
Total & 244 & 8715 \\
\hline Number of profiles per zones & STZ: 3509, SAZ: 2114, \\
& PFZ: 1703, AZ: 1389 & \\
\hline
\end{tabular}

Table 3: Summary of ARGO data by research programs and institutions contributing more than 400 profiles. The period of study is 2004-2008.

\begin{tabular}{cccc}
\hline Parameter & $\begin{array}{c}\text { Spatial } \\
\text { Resolution }\end{array}$ & $\begin{array}{c}\text { Temporal } \\
\text { Resolution }\end{array}$ & Instrument, Source \\
\hline Sea Surface Temperature & $0.25^{\circ}$ & 3 days & AMSR-E, Remote Sensing Systems, http://www.remss.com/ \\
Wind Stress & $0.5^{\circ}$ & Daily & QuikSCAT, Ifremer, Cersat, http://www.ifremer.fr/cersat/ \\
$\begin{array}{c}\text { Absolute Surface Geostrophic } \\
\text { Velocity }\end{array}$ & $0.33^{\circ}$ & Weekly & $\begin{array}{c}\text { Merged Altimeters, Delayed Time AVISO } \\
\text { http://www.aviso.oceanobs.com/ }\end{array}$ \\
$\begin{array}{c}\text { Lateral Eddy Diffusion } \\
\text { Coefficient }\end{array}$ & $5^{\circ}$ lon $1^{\circ}{ }^{\circ}$ lat & Climatology & Surface Drifters, Sallée et al. (2008b) \\
$\begin{array}{c}\text { Turbulent Air-sea Fluxes } \\
\text { Latent and Sensible }\end{array}$ & $1^{\circ}$ & Daily & OAFlux project, WHOIhttp://oaflux.whoi.edu/ \\
$\begin{array}{c}\text { Radiative Air-sea Fluxes } \\
\text { Shortwave and Longwave }\end{array}$ & $2.5^{\circ}$ & Daily & International Satellite Cloud Climatology \\
Projecthttp://isccp.giss.nasa.gov/
\end{tabular}

Table 4: Summary of data and reanalysis gridded products used to compute the forcing terms in equation (1). 


\begin{tabular}{ccc|cccc}
\hline & $\begin{array}{c}\text { Heat content } \\
\text { variations } \\
\text { (from ARGO floats) }\end{array}$ & $\begin{array}{c}\text { Heat content variations } \\
\text { (sum of forcing terms) }\end{array}$ & $\begin{array}{c}\text { Air-sea } \\
\text { fluxes }\end{array}$ & $\begin{array}{c}\text { Ekman } \\
\text { advection }\end{array}$ & $\begin{array}{c}\text { Lateral eddy } \\
\text { diffusion }\end{array}$ & $\begin{array}{c}\text { Geostrophic } \\
\text { advection }\end{array}$ \\
\hline STZ & $-49 \pm 35$ & $-69 \pm 28$ & -35 & -23 & -47 & 36 \\
SAZ & $-9 \pm 38$ & $15 \pm 43$ & 18 & -67 & 104 & -40 \\
PFZ & $-19 \pm 17$ & $17 \pm 35$ & 42 & -50 & 3 & 22 \\
AZ & $-12 \pm 10$ & $21 \pm 19$ & 38 & -20 & 8 & -5 \\
\hline
\end{tabular}

Table 5: Mean (yearly) values of the heat content variations (estimated from the ARGO profiles and as the sum of the forcing terms) and their contributing terms. These mean values were computed from the monthly values shown in Figure 8.

\begin{tabular}{ccc}
\hline Zone & Mean & rms \\
\hline Sub Tropical Zone & $20 \pm 41$ & 24 \\
Subantarctic Zone & $-20 \pm 65$ & 57 \\
Polar Frontal Zone & $-42 \pm 41$ & 49 \\
Antarctic Zone & $-29 \pm 20$ & 43 \\
\hline
\end{tabular}

Table 6: Mean and root mean square residuals (heat content variation minus the sum of the forcing terms) of the heat budget equations in each zone $\left(\mathrm{Wm}^{-2}\right)$, directly estimated from the elementary (over 3 float cycles) budget computations. 


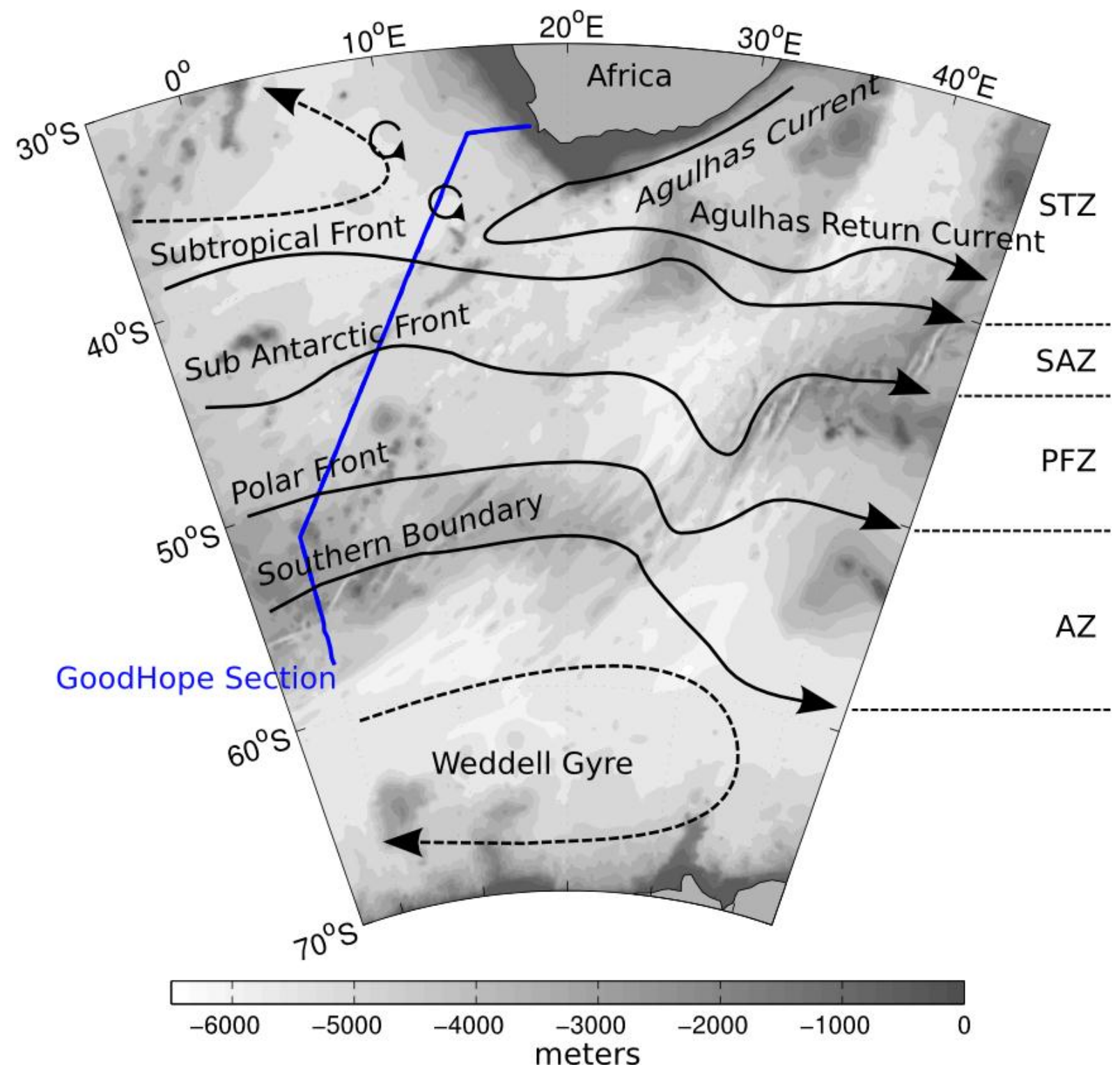

Figure 1: The area of study, showing the bathymetry and main (schematic) fronts, circulation patterns. The quasi-meridional continuous line on the left shows the repeat hydrographic transect of the GoodHope project (named the GoodHope line). Acronym meanings are: STZ, Subtropical Zone, SAZ, Subantarctic Zone; PFZ, Polar Frontal Zone; AZ, Antarctic Zone. 

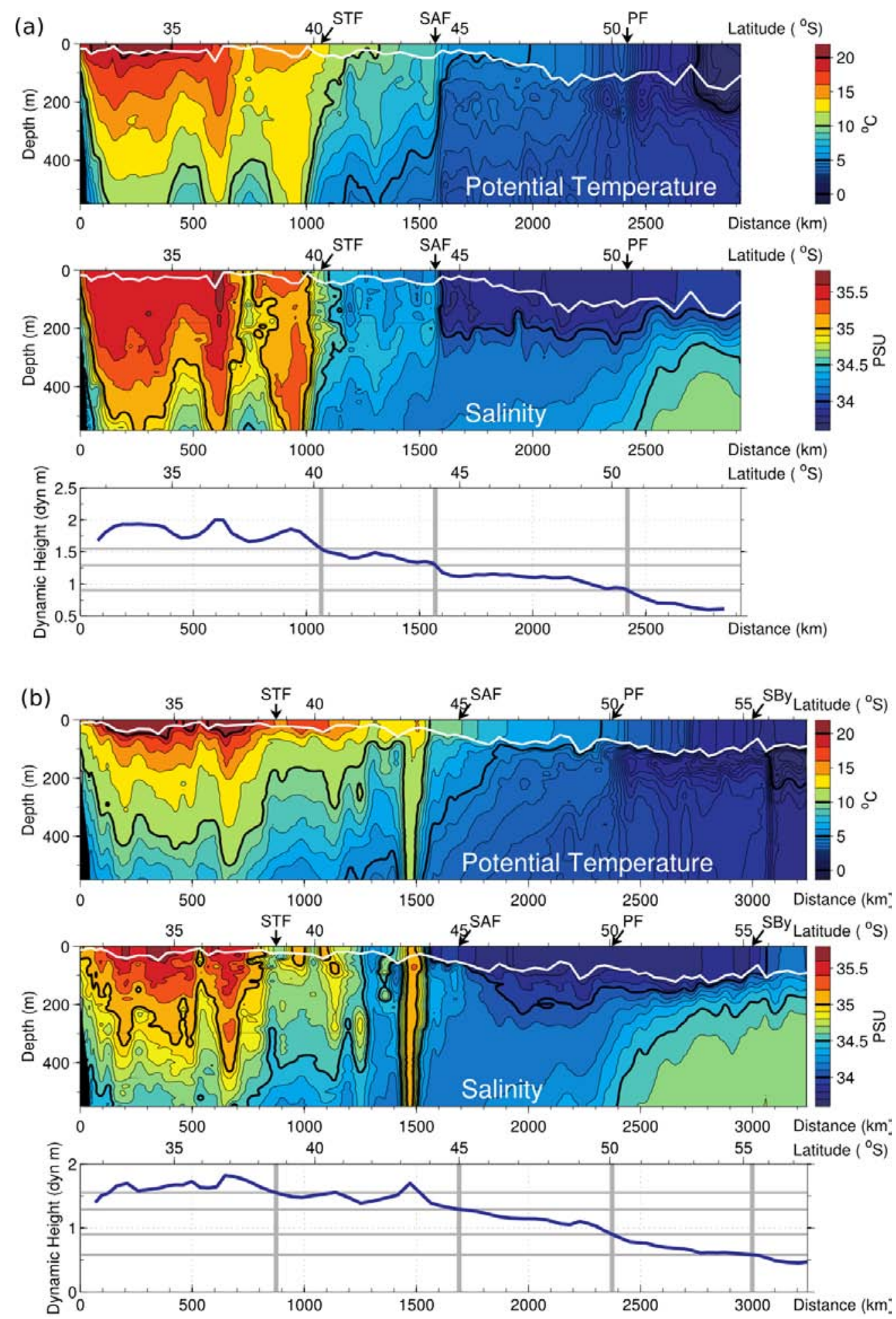

Figure 2: Vertical distribution of potential temperature and salinity, and variations of the surface dynamic height referenced to $1500 \mathrm{dbar}$, for two realizations of the hydrographic GoodHope transect shown in Figure 1. (a) Cruise 19 (November 8-25, 2004) of R/V Akademik Sergey Vavilov of the Shirshov Institute of Oceanology. (b) Cruise BONUS/GoodHope (February 13 to March 16, 2008) of R/V Marion Dufresne. 

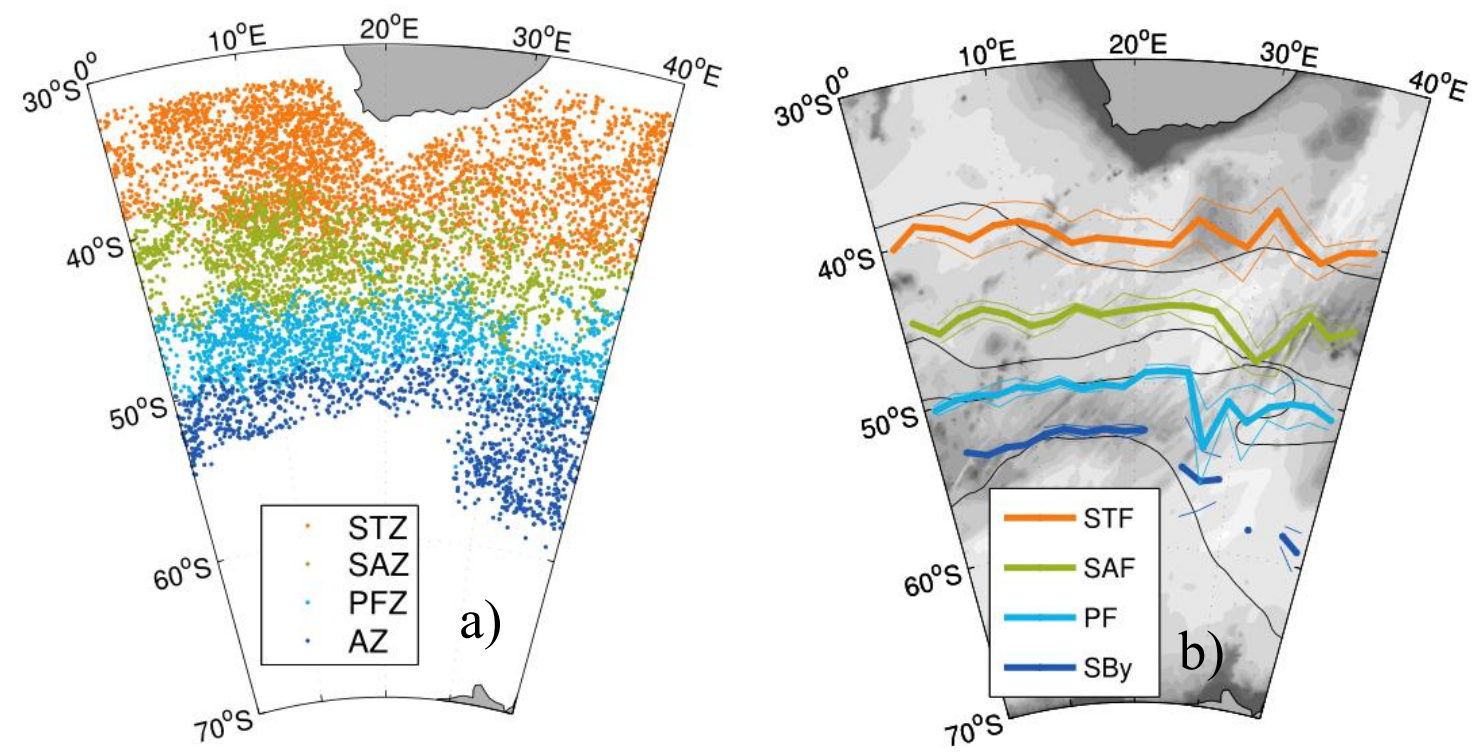

Figure 3: (a) Location of all ARGO profiles used to compute the SML rate of change. The colour code gives the dynamic height referenced to $1500 \mathrm{dbar}$, which was used to allocate a frontal zone to each profile. (b) Front locations (STF, SAF, PF, SBy) as determined from ARGO floats which happened to cross the fronts. The thick (thin) coloured lines show the averaged latitudes (plus/minus one standard deviation intervals) in 2 degrees longitude bins. Also shown are the climatological fronts from Orsi et al. (1995) (thin black lines) and bathymetric outlines. 

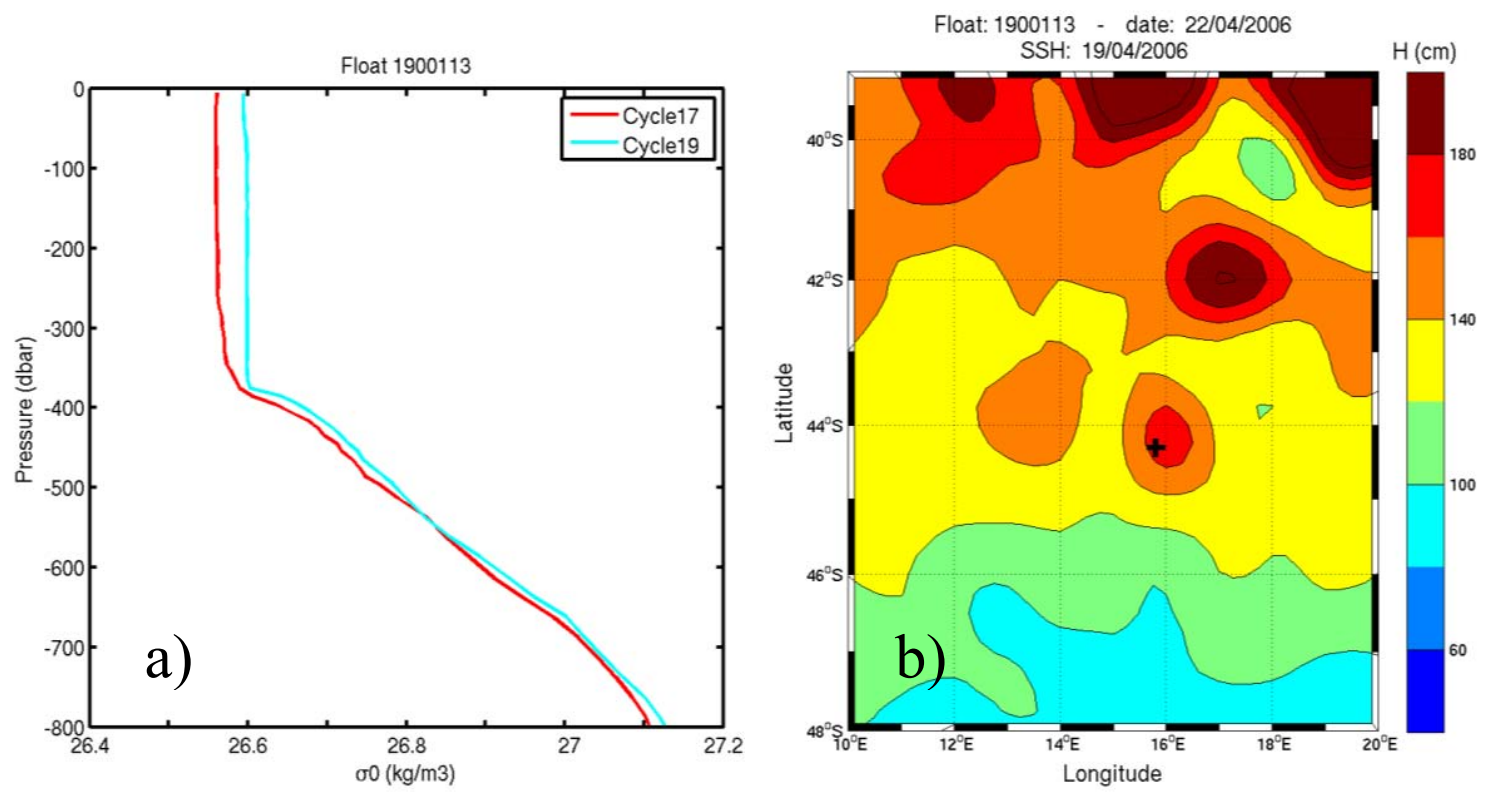

Figure 4: (a) Density $\left(\sigma_{0}\right)$ profiles from two cycles (20 days apart) of ARGO float No1900113 in the SAZ south of Africa, revealing a $390 \mathrm{~m}$ deep surface mixed layer. (b) ARGO profile location for one of these cycles (22 April 2006) superimposed on the nearly concomitant (19 April 2006) AVISO sea surface height map, showing that the deep mixed layer occurred in the core of an anticyclone. 


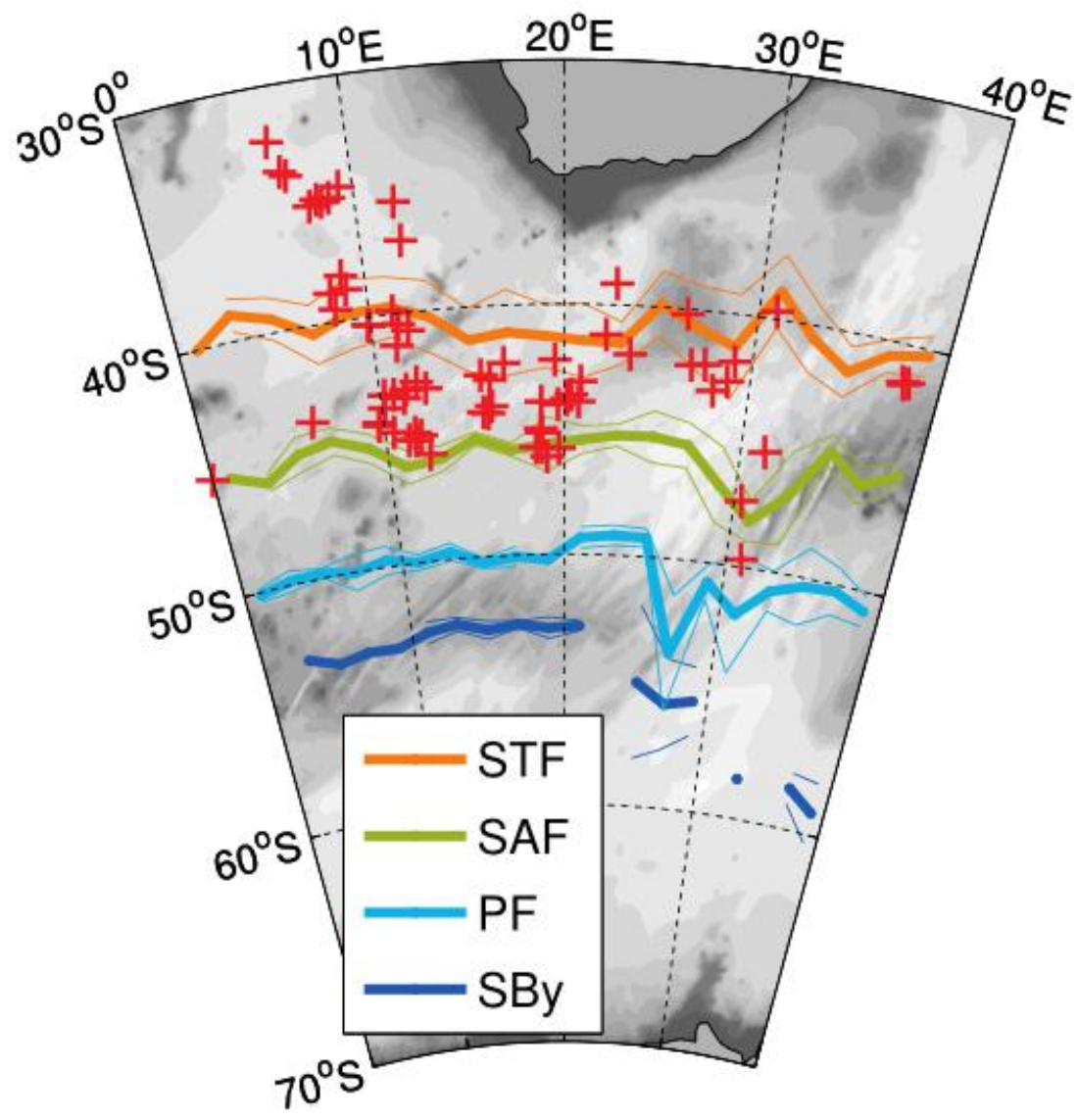

Figure 5: Locations of ARGO profiles with surface mixed layer depths larger than $250 \mathrm{~m}$. Also shown are the ARGO-inferred frontal patterns and bathymetric outlines. 

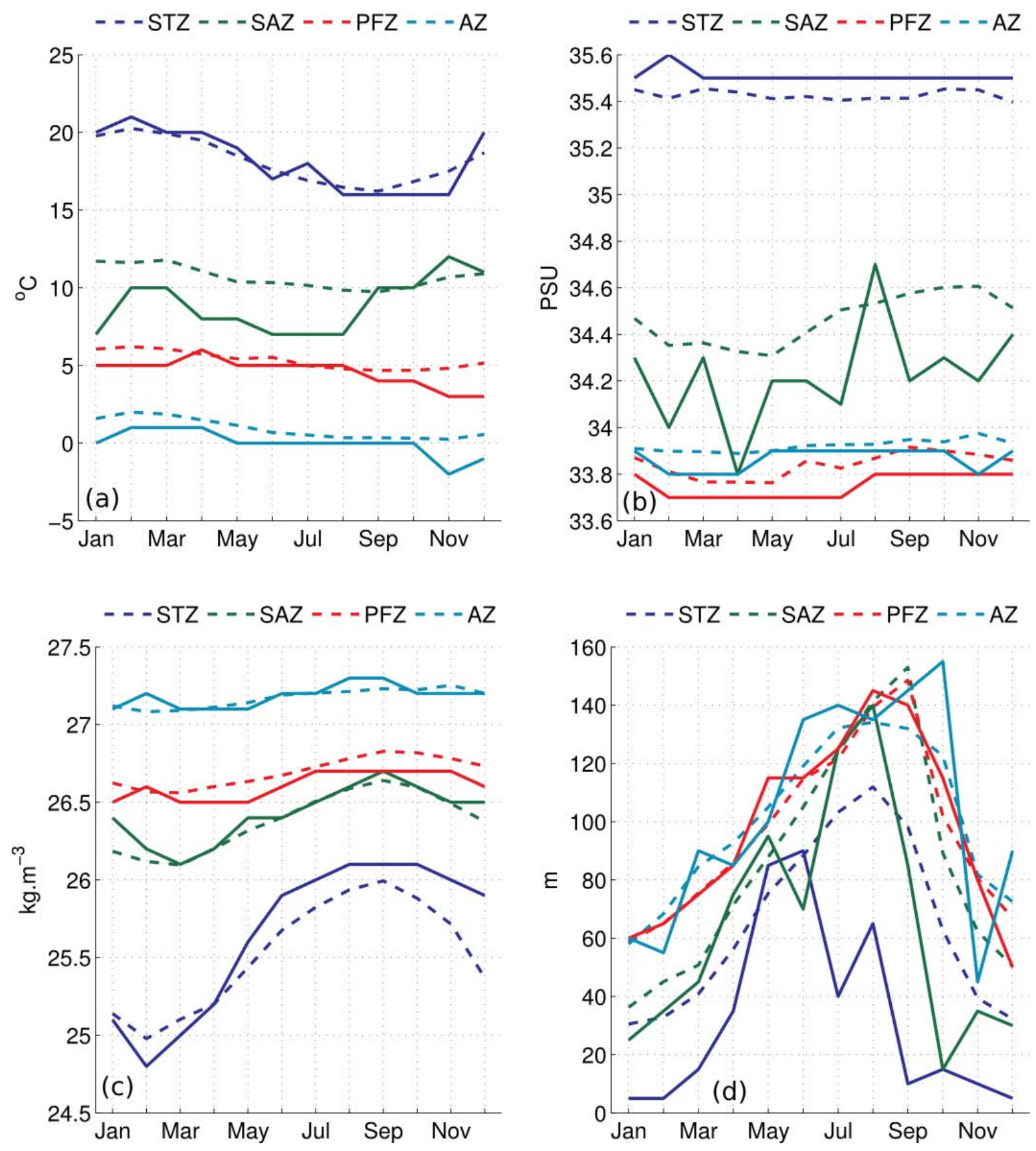

Figure 6: Seasonal variations of SML properties in the frontal zones. (a) Potential temperature, (b) salinity, (c) potential density, (d) mixed layer depth. The dashed (continuous) lines show the monthly climatological means (statistical modes). The statistical modes were determined by computing monthly histograms with bin widths of $1^{\circ} \mathrm{C}, 0.1 \mathrm{psu}, 0.1 \mathrm{~kg} \mathrm{~m}^{-3}$, and $5 \mathrm{~m}$, for temperature, salinity, density and SML depth, respectively. 
a)
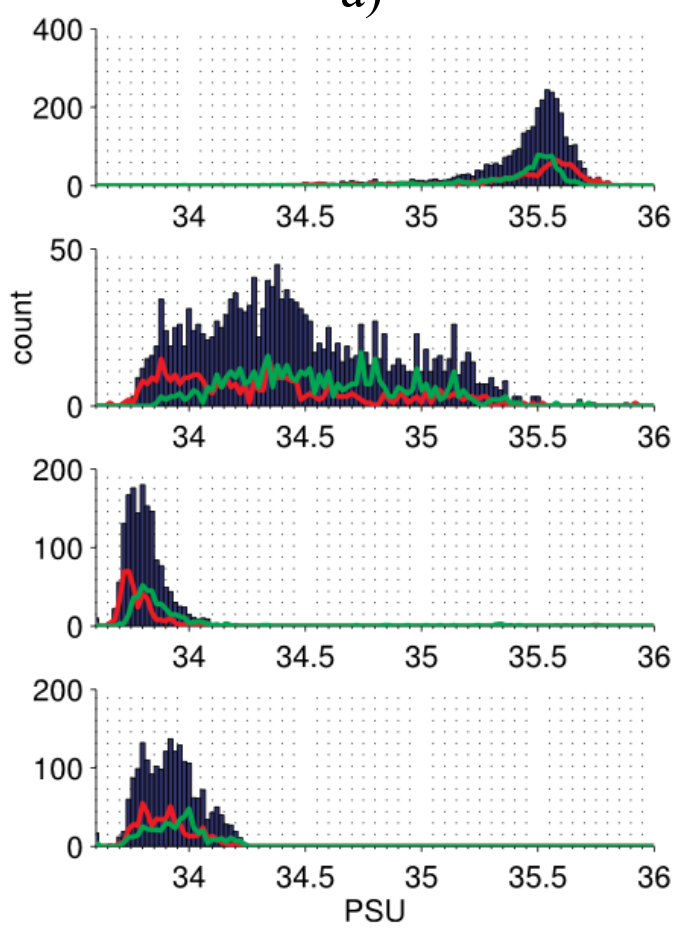

b)
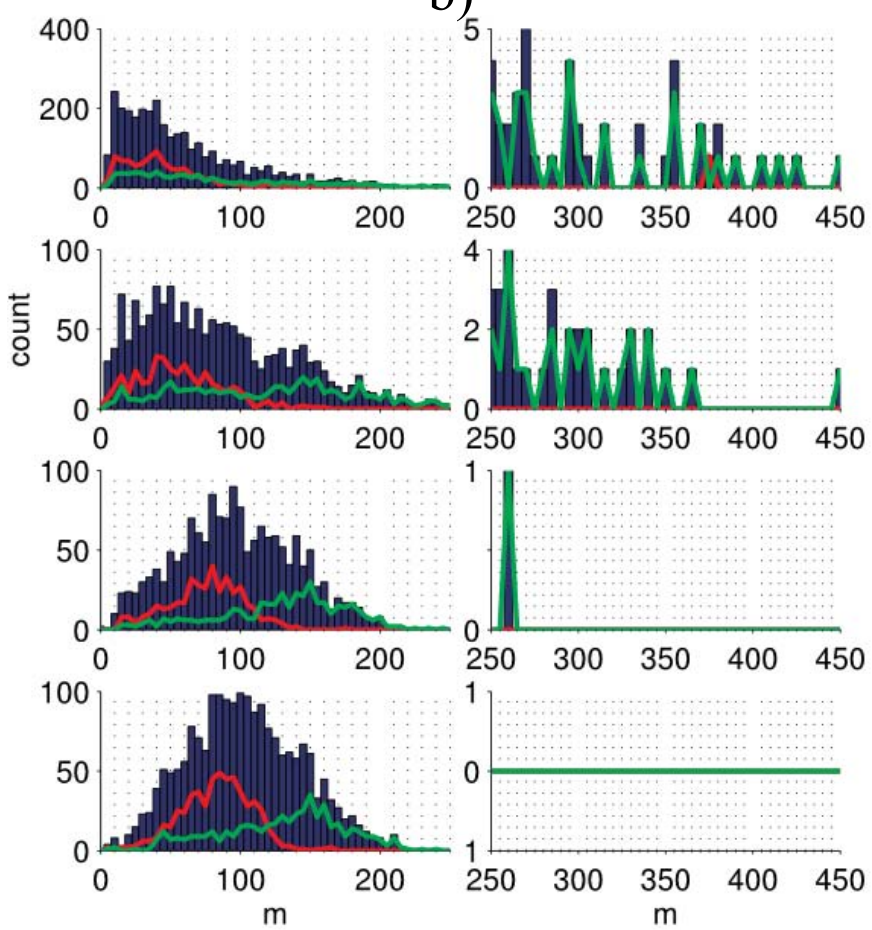

Figure 7: Yearly histograms of surface mixed layer salinity (a) and depth (b) in each frontal zone. Superimposed are the late summer (Feb-Mar-Apr; red lines) and late winter (Aug-Sept-Oct; green lines) distributions. Also shown in (b) are expanded views of the tails of the distributions (depths in excess of $250 \mathrm{~m}$ ). 


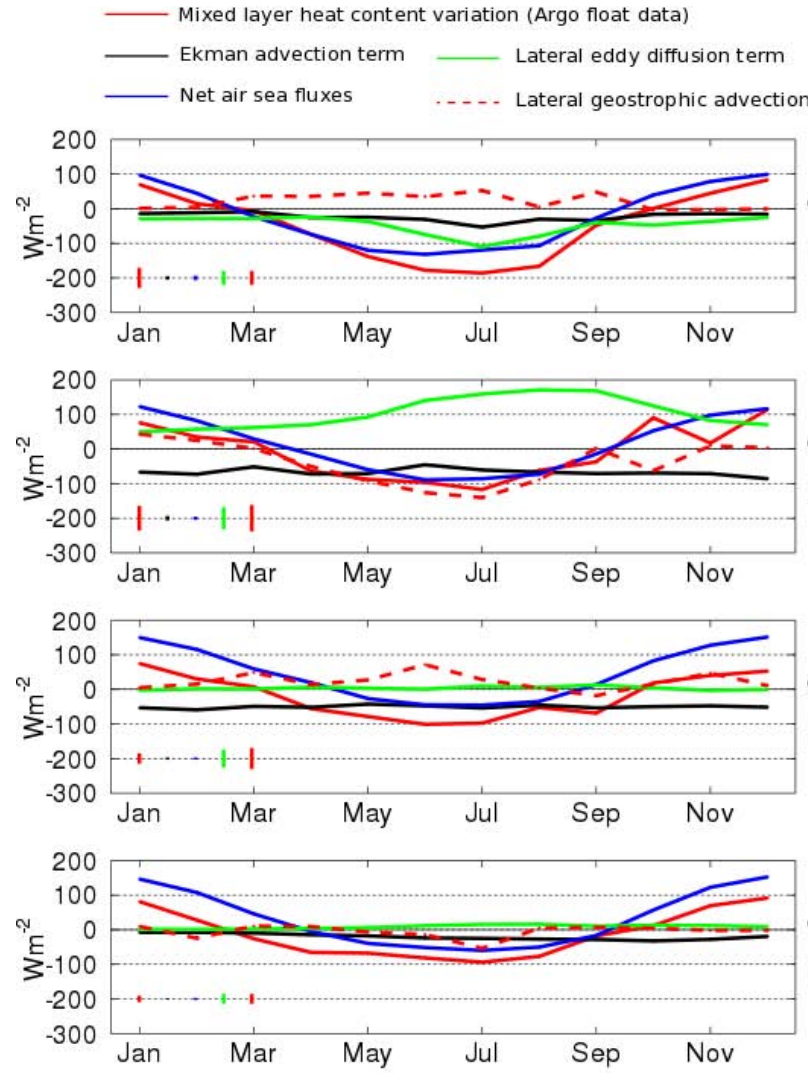

(a)
Sum of forcing terms

Mixed layer heat content variation (Argo float data)
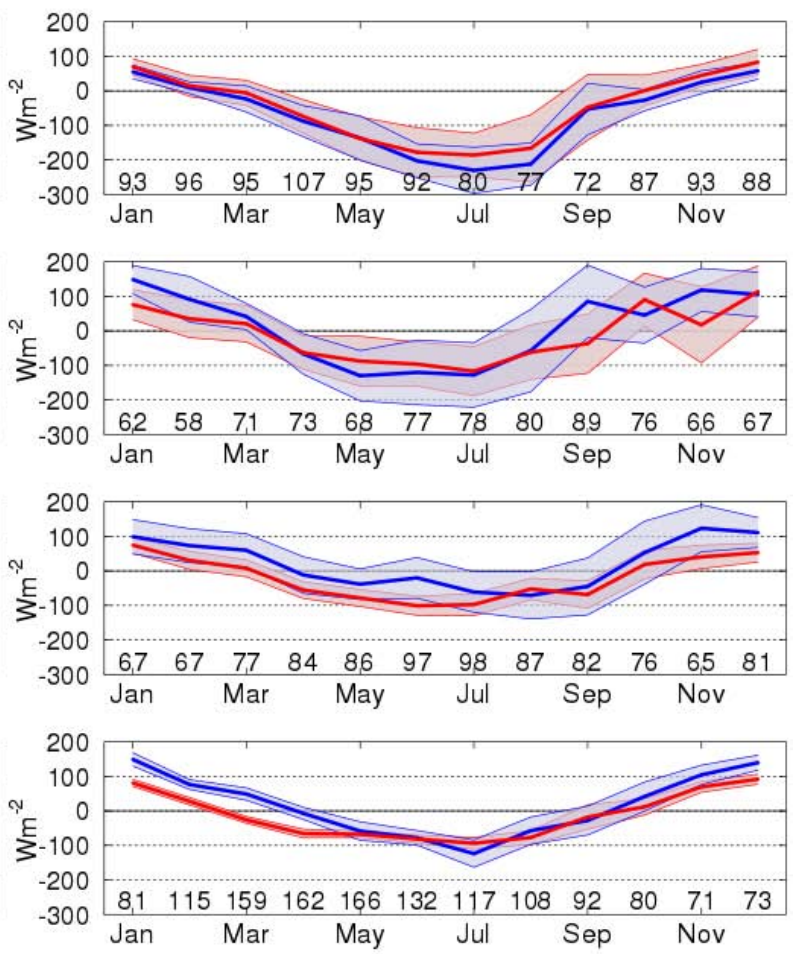

(b)

Figure 8: Seasonal variations of the SML heat budget terms of equation (1), averaged over the period 2004-2008. (a) The SML heat rate of change (left hand side of equation (1)) is shown along with each forcing term. (b) The heat rate of change is shown along with the sum of the forcing terms. Uncertainties were computed assuming that the number of independent individual heat budget estimates was one fifth of the number of ARGO profiles each month (see text). 


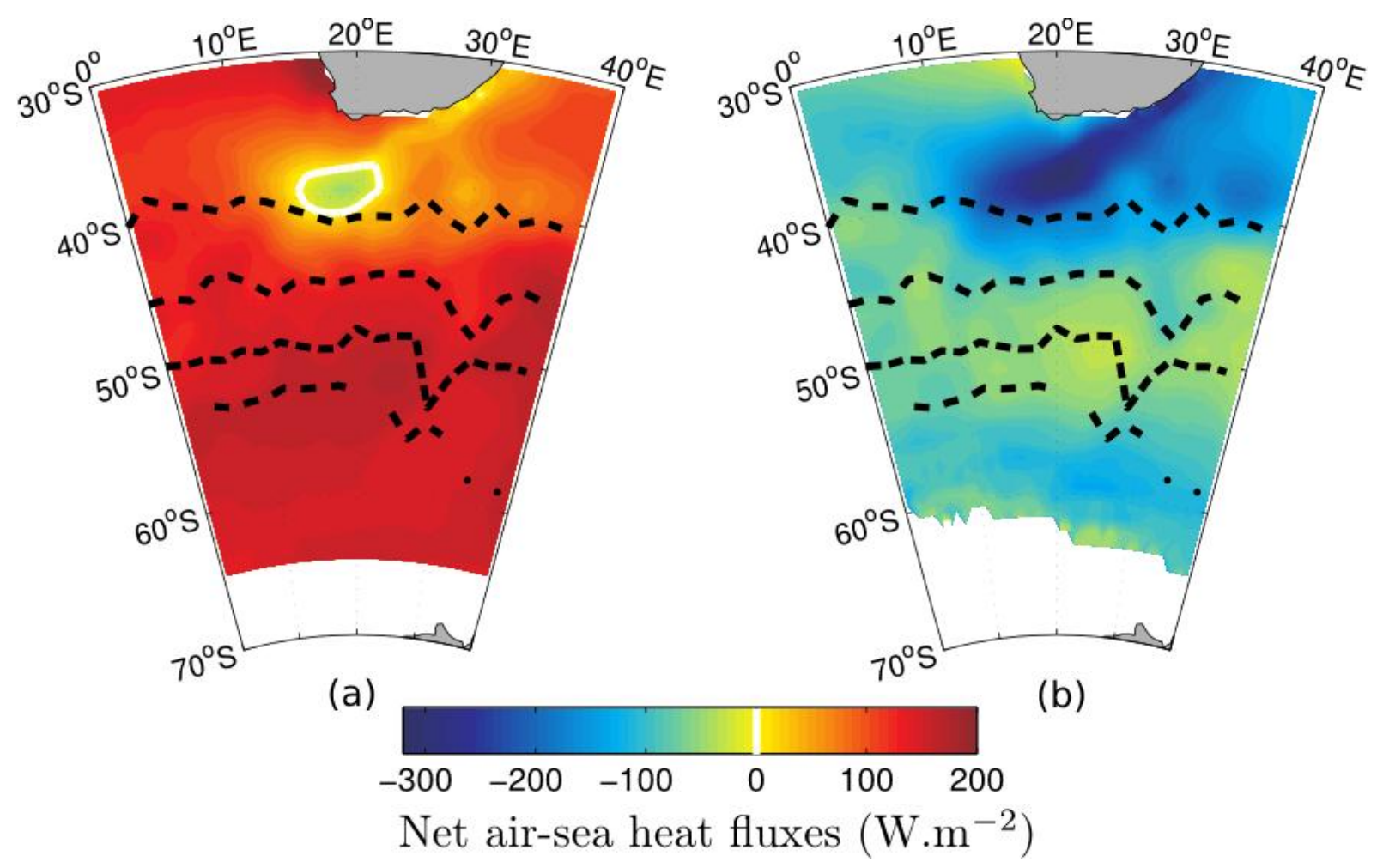

Figure 9: Net air-sea heat fluxes $\left(\mathrm{Wm}^{-2}\right)$ for January (a) and July (b), averaged over the period 2004-2008. The ARGO-inferred mean tracks of the STF, SAF, PF, and SBy are also shown. 


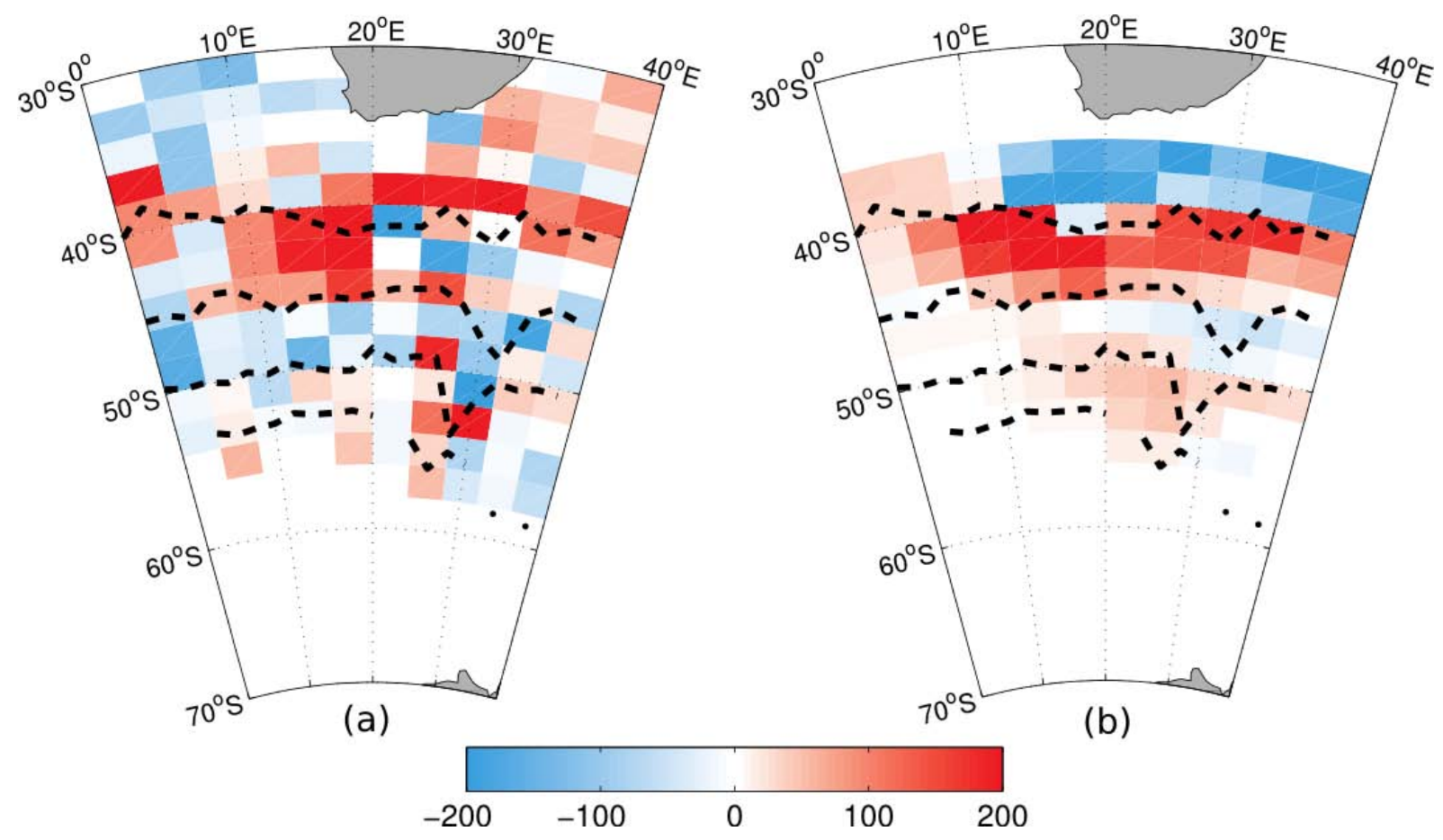

Figure 10: (a) Geographical distribution of the residuals of equation (1) with the lateral diffusion term omitted. (b) Geographical distribution of the lateral diffusion term using the diffusivities of Sallée et al. (2008b). 

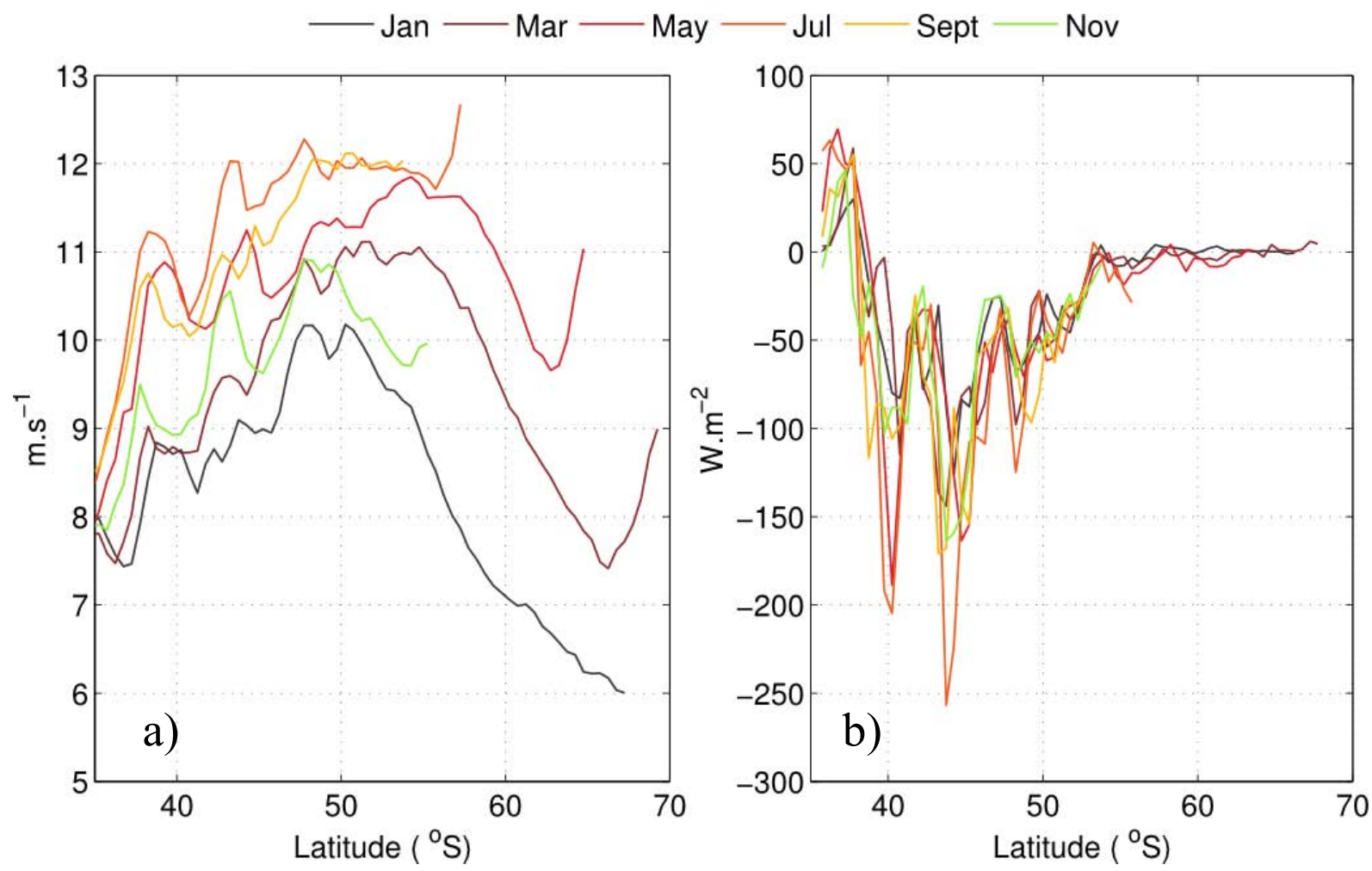

Figure 11: (a) Seasonal variations of the latitudinal distribution of wind speed at $20^{\circ} \mathrm{E}$. One curve every two months is shown, starting January, with the following colour code: Black for January, brown for March, red for May, orange for July, light orange for September and yellow for November. (b) Seasonal variations of the Ekman advection term of equation (1), with a colour code similar to (a). 
(a) Net Radiative Fluxes

a)

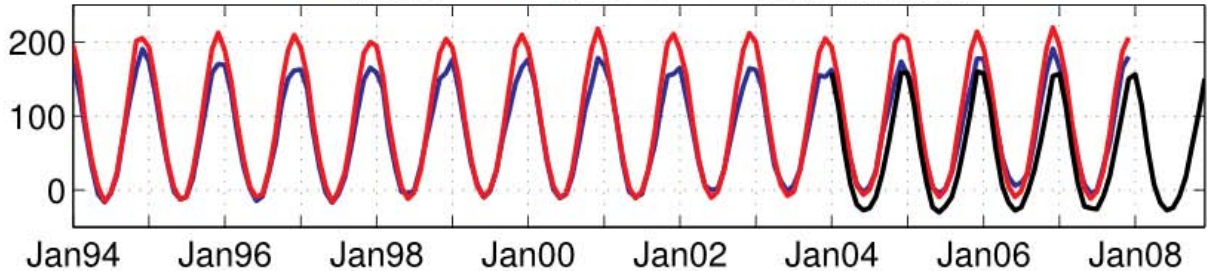

(b) Latent Heat Fluxes

b)

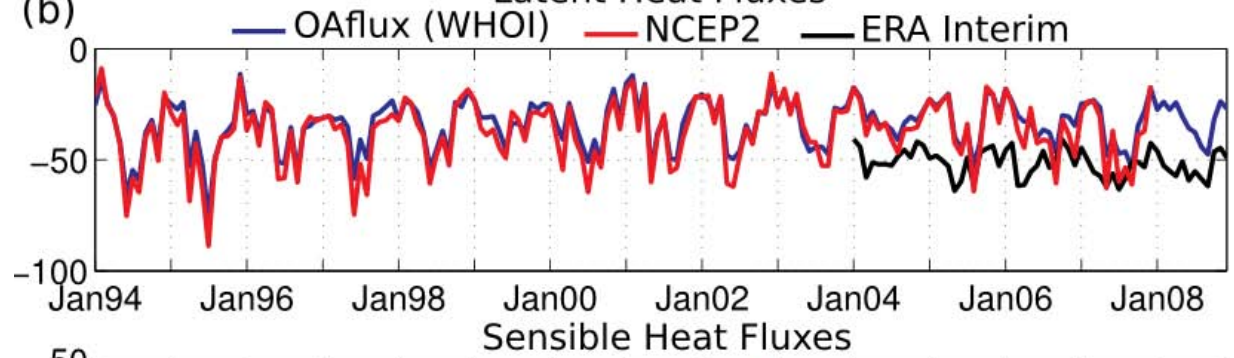

c)

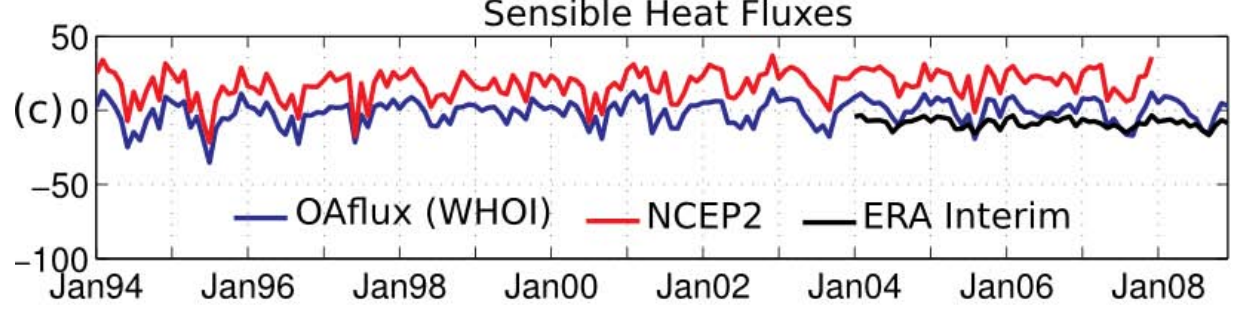

(d)

Net Heat Fluxes

d)

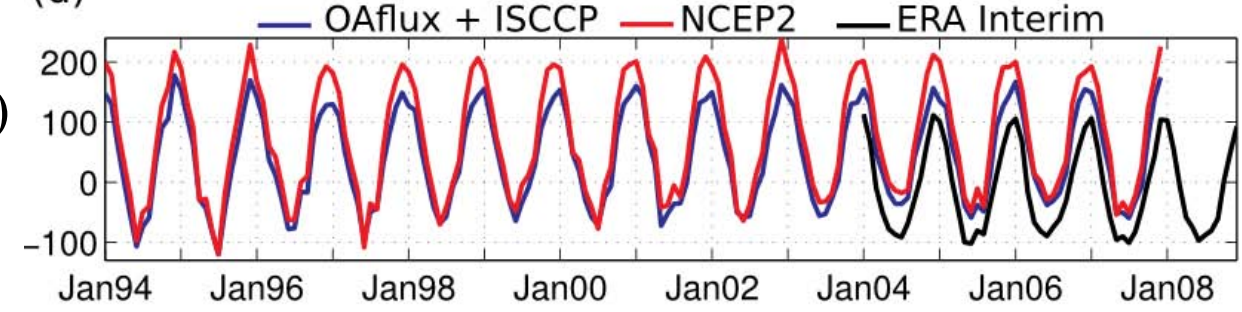

(e)

Differences

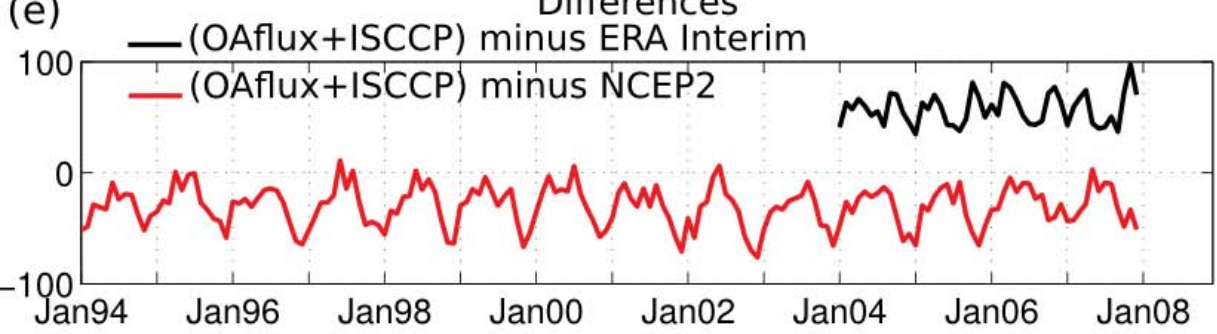

Figure 12: Comparisons of products used to compute the net air-sea fluxes, for the PFZ and between $0^{\circ} \mathrm{E}$ and $40^{\circ} \mathrm{E}$. (a) Net surface radiative fluxes ISCCP, NCEP2, and ERA-Interim. (b) Latent heat flux products OAflux, NCEP2 and ERA-Interim. (c) The three sensible heat fluxes. (d) Net surface heat fluxes OAflux+ISCCP, NCEP2 and ERA-Interim. (e) Differences between the OAflux+ISCCP net fluxes and the two other products shown in (d). 